\title{
Application of Single-Station Sigma and Site-Response Characterization in a Probabilistic Seismic-Hazard Analysis for a New Nuclear Site
}

\author{
by A. Rodriguez-Marek, E. M. Rathje, J. J. Bommer, F. Scherbaum, and P. J. Stafford
}

\begin{abstract}
Aleatory variability in ground-motion prediction, represented by the standard deviation (sigma) of a ground-motion prediction equation, exerts a very strong influence on the results of probabilistic seismic-hazard analysis (PSHA). This is especially so at the low annual exceedance frequencies considered for nuclear facilities; in these cases, even small reductions in sigma can have a marked effect on the hazard estimates. Proper separation and quantification of aleatory variability and epistemic uncertainty can lead to defensible reductions in sigma. One such approach is the single-station sigma concept, which removes that part of sigma corresponding to repeatable site-specific effects. However, the site-to-site component must then be constrained by site-specific measurements or else modeled as epistemic uncertainty and incorporated into the modeling of site effects. The practical application of the single-station sigma concept, including the characterization of the dynamic properties of the site and the incorporation of site-response effects into the hazard calculations, is illustrated for a PSHA conducted at a rock site under consideration for the potential construction of a nuclear power plant.
\end{abstract}

\section{Introduction}

Probabilistic seismic-hazard analysis (PSHA) is the preferred approach to evaluate potential earthquake motions at the sites of critical facilities such as nuclear power plants, because it provides a rational framework for the capture of uncertainties. Elements of aleatory variability, reflecting inherent (and theoretically irreducible) randomness-such as future earthquake locations-are incorporated directly into the PSHA integrations. Epistemic uncertainties, reflecting lack of knowledge regarding earthquake processes in general and about the site and region under study specifically, are captured through the use of logic trees.

To the extent that resources allow, it should always be an objective to gather geological, seismological, geophysical, and geotechnical data that will reduce the total uncertainty in the hazard estimates. In this regard, there is a clear benefit in ensuring that any element of apparent aleatory variability that is in fact an epistemic uncertainty is, as a first step, removed from the hazard integrations and transferred to the logic-tree formulation. As a second step, newly acquired data may then allow the reduction of this component of the epistemic uncertainty. In this regard, an important development in the last decade is the identification of epistemic components of the aleatory variability in ground-motion prediction equations (GMPEs), commonly referred to as sigma. The concept, in its most general sense, is referred to as nonergodic sigma (Anderson and Brune, 1999) and in its most common application as single-station sigma (Atkinson, 2006). The results of
PSHA are very sensitive to the value of sigma; and, for the low annual exceedance frequencies relevant to defining design motions for nuclear facilities, even small reductions in sigma can bring appreciable benefits (Bommer and Abrahamson, 2006). Pursuing defensible reductions in sigma is worthwhile and also more promising than unjustifiable truncation of the residual distribution by imposing unrealistically low limits on the number of standard deviations considered in PSHA calculations (Strasser et al., 2008).

This paper presents a framework for implementing the concept of single-station sigma and its intimate relationship to the site-response characterization. After explaining the framework, the practical application of the approach is illustrated through a case history for a nuclear power plant site.

\section{Sigma and the Partially Nonergodic Approach}

In applying a GMPE to the assessment of seismic hazard at a specific location, the interest is in the variation of motions at this site due to different earthquakes that could occur over time. Because it is rare to have recordings from the location under study, and even in the few cases for which such recordings exist they will cover at most a few decades, PSHA generally invokes what is called the ergodic assumption (Anderson and Brune, 1999). The ergodic assumption essentially states that variability over space can be used as a substitute for variation over time. It is invoked in practice because the sigma values calculated from regression analyses to develop 
Table 1

Terminology Used for Residual Components and Their Standard Deviations

\begin{tabular}{|c|c|c|c|}
\hline Residual Component & $\begin{array}{l}\text { Residual } \\
\text { Notation }\end{array}$ & Standard Deviation Component & $\begin{array}{l}\text { Definition of Standard } \\
\text { Deviation Component* }\end{array}$ \\
\hline Total residual & $\Delta_{e s}$ & Total or ergodic standard deviation & $\sigma_{\text {ergodic }}=\operatorname{std}\left(\Delta_{e s}\right)$ \\
\hline Event term & $\delta B_{e}$ & Between-event (or interevent) standard deviation (tau) & $\tau=\operatorname{std}\left(\delta B_{e}\right)$ \\
\hline Event-corrected residual & $\delta W_{e s}$ & Within-event (or intraevent) standard deviation (phi) & $\phi=\operatorname{std}\left(\delta W_{e s}\right)$ \\
\hline Site term & $\delta S 2 S_{s}$ & Site-to-site variability & $\phi_{S 2 S}=\operatorname{std}\left(\delta S 2 S_{S}\right)$ \\
\hline Site- and event-corrected residual & $\delta W S_{e s}$ & $\begin{array}{l}\text { Event-corrected single-station standard deviation } \\
\quad \text { (single-station phi) }\end{array}$ & $\phi_{s s}=\operatorname{std}\left(\delta W S_{e s}\right)$ \\
\hline
\end{tabular}

$* \operatorname{std}(\cdot)$ denotes the standard deviation operator.

GMPEs represent the variability over space (i.e., across many different sites and sometimes many regions), yet the resulting models are applied to a single site. However, multiple recordings from similar events recorded at individual sites generally display lower variability than indicated by the sigma values of GMPEs (e.g., Atkinson, 2006; Rodriguez-Marek et al., 2011). The reason for these differences is that there are site-to-site variations among sites characterized by the same site parameterization (e.g., $V_{S 30}$ value), and these variations are included within the sigma values of GMPEs, but these variations are not present when considering a single site.

If the repeatable contributions to the seismic motion at the site of interest (i.e., the site term) can be modeled through an appropriate adjustment to the median ground-motion predictions, then the sigma value can be reduced by an amount that reflects the variability in the site term. The resulting value of sigma is referred to as single-station sigma (Atkinson, 2006). The single-station sigma concept can only be invoked if the site term is known with accuracy or if epistemic uncertainty in the site term is incorporated into the PSHA. In such a case, the net effect on the mean hazard is expected to be close to zero because the increased epistemic uncertainty is balanced by the decreased aleatory variability, but nonetheless the application of single-station sigma applies the division between randomness and uncertainty more completely. The ergodic assumption effectively folds the epistemic uncertainty regarding individual site terms into the sigma value of the GMPE, representing it as aleatory variability.

The development of the single-station sigma concept is presented using the notation of Al Atik et al. (2010). Total residuals $\left(\Delta_{e s}\right)$, defined as the difference between recorded ground motions and the values predicted by a GMPE (in natural $\log$ units), are separated into a between-event term $\left(\delta B_{e}\right)$ and a within-event term $\left(\delta W_{e s}\right)$ :

$$
\Delta_{e s}=\delta B_{e}+\delta W_{e s},
$$

in which the subscripts denote an observation for event $e$ at station $s$. The terms $\delta B_{e}$ and $\delta W_{e s}$ have standard deviations $\tau$ and $\phi$, respectively. The within-event residuals can in turn be separated into

$$
\delta W_{e s}=\delta S 2 S_{s}+\delta W S_{e s},
$$

in which $\delta S 2 S_{s}$ represents the systematic deviation of the observed ground motion at site $s$ (i.e., the site term) from the median event-corrected ground motion predicted by the GMPE, and $\delta W S_{e s}$ is the site- and event-corrected residual. The standard deviations of the $\delta S 2 S_{s}$ and $\delta W S_{e s}$ terms are denoted by $\phi_{S 2 S}$ and $\phi_{s s}$, respectively. Table 1 summarizes the components of the total residual, their respective standard deviations, and the terminology used for each standard deviation component.

In traditional (i.e., ergodic) PSHA, all of the residual components are considered as part of the aleatory variability, such that

$$
\sigma_{\text {ergodic }}=\sqrt{\tau^{2}+\phi_{s s}^{2}+\phi_{S 2 S}^{2}}
$$

In the partially nonergodic approach, the site term $\left(\delta S 2 S_{s}\right)$ is assumed to be known (or knowable), and hence its standard deviation $\left(\phi_{S 2 S}\right)$ is excluded from equation (3). The reason this is partially nonergodic rather than fully nonergodic is that there is a path component that also contributes to variability at a site, and only if this path-to-path variability is removed can the approach be considered fully nonergodic. The standard deviation for the partially nonergodic approach is known as the single-station sigma and is given by

$$
\sigma_{s s}=\sqrt{\tau^{2}+\phi_{s s}^{2}}
$$

The principal motivation to adopt a partially nonergodic PSHA approach in a site-specific hazard study is to clearly separate aleatory variability and epistemic uncertainty. An additional motivation is to avoid double counting uncertainty. This double counting results if the site-to-site variability $\left(\phi_{S 2 S}\right)$ is included in the total sigma (see equation 3 ), and in addition the site term is assigned an epistemic uncertainty. A corollary benefit of adopting a partially nonergodic approach is that the value of single-station phi $\left(\phi_{s s}\right)$ has proven to be relatively constant across different regions and tectonic environments (Rodriguez-Marek et al., 2013); hence, estimates from other regions can be applied to regions in which the paucity of recordings preclude regional estimates.

The essential requirements to apply a partially nonergodic PSHA approach are (1) the median value of the site term $\left(\delta S 2 S_{s}\right)$ must be properly estimated for the site under 
analysis, and both (2) the epistemic uncertainty in the site term and (3) the epistemic uncertainty in the single-station sigma must be taken into account. The Estimation of the Site Term and its Epistemic Uncertainty section presents the means by which the site term and its epistemic uncertainty can be computed.

\section{Estimation of the Site Term and its Epistemic Uncertainty}

The site term represents the average deviation of ground motions at a site from the predictions of the GMPE. The median site term at a location where hazard is computed can be quantified if an instrument is located at the site and sufficient measurements are made. The uncertainty on the site term can also be estimated from the measurements using standard statistical tools. Unfortunately, very few sites where PSHA is conducted have instruments at the site that permit these types of estimates. Alternatively, the site term can be estimated numerically.

A key component of the site term is the response of nearsurface materials. Site-response effects are typically quantified by amplification factors (AFs), which represent the ratio of the spectral acceleration at a given spectral period at the surface divided by the spectral acceleration at the same period at the reference rock velocity horizon. Site-response simulations are used to compute AFs for the site-specific conditions. Computed AFs will vary for a site based on differences in input motions and variability/uncertainty in the dynamic properties (i.e., shear-wave velocity, nonlinear shear modulus reduction, and damping curves). This variability in AFs contributes to the epistemic uncertainty of the site term and, once estimated from the site-response analyses, can be incorporated into the hazard calculation using a convolution approach. This approach convolves the hazard curves for reference rock with the AFs and their variability to generate hazard curves for the final target horizon at which ground motions are required (Bazzurro and Cornell, 2004). The application of such a convolution, incorporating the full variability and uncertainty in both the rock hazard and the site response, is referred to as Approach 3 in the U.S. nuclear industry (McGuire et al., 2001). A key advantage of this approach is that it fully preserves the probabilities calculated at the baserock level and faithfully transfers these to the surface motions.

The role of site-response analysis in the convolution approach is to develop an $\mathrm{AF}$ relationship that predicts $\mathrm{AF}$ at each spectral period as a function of the spectral acceleration at the reference rock velocity horizon $\left(\mathrm{Sa}_{\mathrm{r}}\right)$ at the same period. A significant number of site-response analyses are performed using a suite of input motions that spans the range of $\mathrm{Sa}_{\mathrm{r}}$ indicated by the rock hazard curves. In addition, the properties of the site (i.e., shear-wave velocity, layering, shear modulus reduction, and damping curves) are varied via Monte Carlo simulation to incorporate the variability and uncertainty in the site characteristics. The AF predictive relationship and its standard deviation (in natural logarithmic units) are developed by statistical regression of the AF data from the site-response analyses.

In addition to capturing the effects of shallow deposits, the site term must account for the deep shear-wave velocity $\left(V_{S}\right)$ structure and the site attenuation parameter $\left(\kappa_{0}\right)$ (Ktenidou et al., 2013). The contribution of the deep rock column to the site term was demonstrated by Rodriguez-Marek et al. (2011), in which it was shown that borehole records located at stiff rock sites had site terms that varied significantly from site to site. The effects of the deep $V_{S}$ structure and of $\kappa_{0}$ can be captured by accounting for the differences between the target site profile and the reference (host) profile for the GMPE (e.g., Cotton et al., 2006). This adjustment is called a $V_{S}$-kappa $\left(V_{S}-\kappa\right)$ correction, in which kappa represents the full path attenuation combining the effects of site kappa, $\kappa_{0}$, and $Q$ (e.g., Van Houtte et al., 2011).

The selection of the host $V_{S}$ profile and $\kappa_{0}$ value must be such that these are consistent with the host GMPEs. The anchoring $V_{S 30}$ value for the host profile reflects a balance between $V_{S 30}$ values that are well constrained by data (which typically are smaller $V_{S 30}$ values), and larger $V_{S 30}$ values that would minimize the effect of the $V_{S}$-kappa correction factors. The host $\kappa_{0}$ value must be compatible with the host GMPE and can be selected from stochastic parameter inversions from ground-motion recordings, stochastic parameter inversions, empirical GMPEs (Scherbaum et al., 2006), or GMPE-derived Fourier amplitude spectra (FAS) using inverse random vibration theory (RVT) (e.g., Rathje et al., 2005). The target $V_{S}$ profile and $\kappa_{0}$ values should reflect best estimates at the site. In the absence of appropriate measurements, epistemic uncertainty in these values must be taken into account. The epistemic uncertainties in the host and target $V_{S}$ profiles and $\kappa_{0}$ values should be reflected in the total uncertainties in the $V_{S}$-kappa correction factors. These uncertainties are captured in the ground-motion characterization (GMC) logic tree.

\section{Summary of PSHA for the Partially Nonergodic Approach}

Figure 1 summarizes the main components of a PSHA that uses single-station sigma and the partially nonergodic approach. The GMC for the baserock involves the development of a suite of GMPEs for the target baserock conditions and an associated single-station sigma logic tree. The target GMPEs are developed from a group of host GMPEs, each of which is adjusted to account for variations between the host and target $V_{S}, \kappa_{0}$, and $Q$. The single-station sigma logic tree accounts for uncertainty in both $\phi_{s s}$ and $\tau$, which together reflect $\sigma_{s s}$ (equation 4). The values of $\phi_{s s}$ and $\tau$ for the logic tree are selected considering values published in the literature. The baserock GMPEs and single-station sigma values are incorporated into the full logic tree for the PSHA and are used to compute the mean hazard curve for the baserock. 


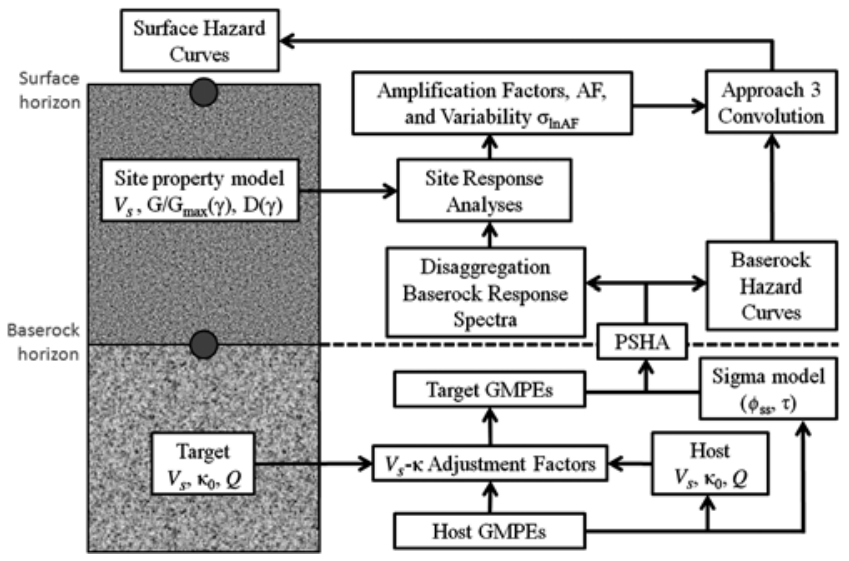

Figure 1. Schematic diagram of the modifications to the host ground-motion prediction equation (GMPE) to obtain site-specific hazard curves.

Site-response analyses are performed to develop site AFs and their variability for each spectral period and for different levels of input motion intensity. The input motions for these analyses are selected to represent the baserock input intensities spanned by the bedrock hazard curves, and these motions must have an appropriate spectral shape for the magnitude and distances indicated by the baserock PSHA disaggregation. The target response spectra for the input motions may be scenario-response spectra generated from the PSHAderived uniform hazard spectra (UHS) and disaggregation or from stochastic simulations and RVT (e.g., Electric Power Research Institute [EPRI], 2013). Each of the input motions is propagated through multiple realizations of the site properties (i.e., $V_{S}$ profile, nonlinear shear modulus reduction, and damping curves) to account for the uncertainty and spatial variability in the dynamic properties across the site. The computed AFs are used to define the probability distribution for $\mathrm{AF}$ (i.e., both median and standard deviation, assuming a lognormal distribution) for each spectral period as a function of the input motion intensity.

Site amplification is incorporated into the hazard calculation through convolution of the baserock hazard curves with the probability density function for the AFs (Bazzurro and Cornell, 2004) to compute surface hazard curves. Convolution allows each baserock ground-motion level to contribute to the hazard for each surface ground-motion level. Using the convolution approach and assuming that $\mathrm{AF}$ is a function solely of the spectral acceleration on rock $\left(\mathrm{Sa}_{\mathrm{r}}\right)$, the hazard for the surface $\left(\lambda_{s}\right)$ is calculated as

$$
\lambda_{s}(z)=\sum_{x_{j}} P\left[\mathrm{AF}>\frac{z}{x_{j}} \mid x_{j}\right] p_{\mathrm{Sa}_{\mathrm{r}}}\left(x_{j}\right)
$$

in which $z$ is the ground-motion level at the surface, $P[\mathrm{AF}>$ $\left.\left(z / x_{j}\right) \mid x_{j}\right]$ is the probability that $\mathrm{AF}$ is greater than $z / x_{j}$ given $\mathrm{Sa}_{\mathrm{r}}=x_{j}$, and $p_{\mathrm{Sa}_{\mathrm{r}}}\left(x_{j}\right)$ is the annual probability of occurrence for $\mathrm{Sa}_{\mathrm{r}}=x_{j}$. For long return periods, this probability is equal to the rate of occurrence of $\mathrm{Sa}_{\mathrm{r}}=x_{j}$, which is approximated by differencing the rates from the computed baserock hazard curve about $\mathrm{Sa}_{\mathrm{r}}=x_{j}$. Through equation (5), all levels of baserock motion (i.e., $x_{j}$ ) contribute to the surface hazard $\lambda_{s}(z)$.

Assuming AF is lognormally distributed, $P[\mathrm{AF} \geq(z / x) \mid x]$ is computed as

$$
P\left[\mathrm{AF} \geq \frac{z}{x} \mid x\right]=\hat{\Phi}\left(\frac{\ln \left[\frac{z}{x}\right]-\mu_{\ln \mathrm{AF} \mid x}}{\sigma_{\ln \mathrm{AF} \mid x}}\right)
$$

in which $\mu_{\ln \mathrm{AF} \mid x}$ is the mean value of the natural logarithm of $\mathrm{AF}$ given $\mathrm{Sa}_{\mathrm{r}}=x$, and $\sigma_{\ln \mathrm{AF} \mid x}$ is the standard deviation of the natural logarithm of $\mathrm{AF}$ given $\mathrm{Sa}_{\mathrm{r}}=x . \hat{\Phi}(\cdot)$ is the standard complementary Gaussian cumulative distribution function. Parameters $\mu_{\ln \mathrm{AF} \mid x}$ and $\sigma_{\ln \mathrm{AF} \mid x}$ are obtained from the siteresponse analyses.

The convolution approach treats all of the site amplification uncertainty/variability as aleatory variability rather than separating epistemic and aleatoric components. However, it is difficult to separate these components for site response, and thus it has become customary to lump all of the site response uncertainty/variability into aleatory variability. Nonetheless, this approach still allows for reductions in variability if more dynamic site characterization is performed, and these data show that less variability should be modeled in the site profile realizations (i.e., Monte Carlo simulations).

\section{Practical Application: The Thyspunt Nuclear Siting Project}

A site-specific PSHA was recently conducted for the Thyspunt site in South Africa, located on the southern coast of the Eastern Cape Province about $90 \mathrm{~km}$ west of Port Elizabeth. The Thyspunt site is under consideration for the construction of a nuclear power plant. The PSHA study was conducted following the requirements of Regulatory Guide 1.208 (U.S. Nuclear Regulatory Commission [USNRC], 2007) within the framework of an SSHAC Level 3 process (Budnitz et al., 1997; USNRC, 2012). The overall organizational structure of the project is presented in Bommer et al. (2013).

Bommer et al. (2014) provides a brief description of the seismic source characterization and GMC models and the databases on which they were based, together with a summary of the hazard results. The discussion below provides only a brief summary of the GMC model (for details see Bommer et al., 2014) and focuses on describing the components that are needed for the partially nonergodic PSHA adopted for the GMC model; namely, the $V_{S}$-kappa correction, the siteresponse analyses, and the sigma model.

\section{Overview of the GMC Model}

There are no strong-motion recordings in South Africa, precluding the possibility of deriving empirical GMPEs for South Africa or using the so-called referenced empirical approach (Atkinson, 2008; Scasserra et al., 2009). After 
opting not to attempt to derive new stochastic GMPEs for South Africa within the timeframe of the Thyspunt PSHA study, the GMC team applied a variant of the hybridempirical approach (Campbell, 2003) for the development of appropriate GMPEs for use in the PSHA. In a broad sense, the hybrid-empirical approach consists of using GMPEs from data-rich host regions and applying adjustments to these equations based on seismological considerations so that they are applicable to the reference rock conditions in the target region. Site-response effects were incorporated into the PSHA using the convolution approach. The reference rock shear-wave velocity horizon for the Thyspunt site is $3000 \mathrm{~m} / \mathrm{s}$ (Bommer et al., 2014).

The GMPEs developed via the hybrid-empirical approach were derived from three backbone GMPEs. The selected backbone GMPEs were Abrahamson and Silva (2008; hereafter referred as AS08), Chiou and Youngs (2008; hereafter referred as CY08), and Akkar and Çağnan (2010; hereafter referred as AC10). For details on the GMPE selection criteria and the adjustments applied to the backbone GMPEs, see Bommer et al. (2014). The only adjustment that is relevant to the partially nonergodic approach is the $V_{S}$-kappa correction, described in detail below.

$V_{S}-$ Kappa Correction. The $V_{S}$-kappa adjustment factors for the response spectra were derived from the components of the theoretical FAS that account for the filter effects of the shear-wave velocity structure, $\kappa_{0}$, and $Q$. The effects of the shear-wave velocity profiles were quantified by the quarterwavelength method (Joyner et al., 1981), the effects of $\kappa_{0}$ were quantified by a $\kappa_{0}$ filter (Anderson and Hough, 1984), and the effects of $Q$ were quantified by a path attenuation filter. The theoretical adjustments to the FAS were applied by multiplication of the host-region FAS and the ratio of the FAS filters for the target and host parameters. The adjusted FAS were converted to response spectra via RVT, and the adjusted response spectra were used with the original response spectra to compute the frequency-dependent adjustment factors for spectral acceleration.

Rather than developing a full suite of stochastic parameters to generate the host-region FAS, as originally proposed by Campbell (2003) for the hybrid-empirical approach, the host-region FAS were derived from acceleration response spectra via inverse RVT (e.g., Gasparini and Vanmarcke, 1976; Rathje et al., 2005). Host-region FAS were generated from response spectra for each backbone GMPE for a scenario earthquake of $M_{\mathrm{w}} 5.75, R_{\mathrm{JB}} 10 \mathrm{~km}$, and $R_{\text {rup }} 12.7 \mathrm{~km}$, a scenario that was based on early disaggregation results using a preliminary hazard model. The host $\kappa_{0}$ associated with each GMPE was computed from the slope of the $\log$ (FAS) versus frequency curve in the frequency range of about 5-15 Hz. Because of deficiencies in the response spectra at frequencies greater than about $20 \mathrm{~Hz}$, the FAS derived via inverse RVT were not reliable at higher frequencies. Therefore, the derived $\kappa_{0}$ values were used to extrapolate the FAS for frequencies greater than $15 \mathrm{~Hz}$.
The host shear-wave velocity profile selected for the $V_{S}$ profile adjustment was the generic California rock profile of Boore and Joyner (1997), which has a $V_{S 30}$ of $618 \mathrm{~m} / \mathrm{s}$. Shear-wave velocity profiles from Turkish strong-motion stations (Sandıkkaya et al., 2010) and crustal profiles in Turkey (Tezel et al., 2010) confirmed that this model was also appropriate for AC10, which is a GMPE developed from Turkish strong-motion recordings. For the target $V_{S}$ profile, the generic eastern North America rock profile of Boore and Joyner (1997) was adopted but adjusted by simple truncation of the profile at shallow depths so that it had a shear-wave velocity of $3000 \mathrm{~m} / \mathrm{s}$ at the surface. This profile was deemed appropriate based on comparison with upper crustal velocities in South Africa reported by Kgaswane et al. (2009). The host $\kappa_{0}$ values for each GMPE were calculated as 0.0397, 0.0372, and $0.0386 \mathrm{~s}$ for AS08, CY08, and AC10, respectively. Based on the analysis of weak-motion recordings at South African sites analogous to the bedrock at the Thyspunt site, three target $\kappa_{0}$ values $(0.0050,0.0030$, and $0.0011 \mathrm{~s})$ were selected. The $\kappa_{0}$ value of $0.0030 \mathrm{~s}$ was inferred from a frequency limit of $40 \mathrm{~Hz}$, which corresponds to the maximum useable frequency in the weak-motion recordings and below which no effects of $\kappa_{0}$ were observed. The other $\kappa_{0}$ values were selected based on values commonly used for hard rock in other parts of the world $\left(\kappa_{0}=0.0050 \mathrm{~s}\right)$ and a maximum frequency of interest of $100 \mathrm{~Hz}\left(\kappa_{0}=0.0011 \mathrm{~s}\right)$. Finally, the $Q$ adjustment was based on a host region $Q$ model for western North America (Campbell, 2003) and a South Africa $Q$ model based on weak-motion inversions (Bommer et al., 2014).

The $V_{S}$-kappa adjustments are summarized in Figure 2. The FAS derived from inverse RVT for the three GMPEs and used to estimate the host $\kappa_{0}$ values are shown in Figure 2a. The original and adjusted FAS are shown in Figure $2 b$. The adjusted FAS are smaller than the original FAS at frequencies less than about $7 \mathrm{~Hz}$ because of the larger shear-wave velocity in the target region, whereas the adjusted FAS are larger than the original FAS at higher frequencies due to the smaller $\kappa_{0}$. The calculated $V_{S}$-kappa adjustment factors for response spectral acceleration for the three GMPEs and three target $\kappa_{0}$ are shown in Figure 2c.

A point worth emphasizing is that there are clearly uncertainties in both the host and target $V_{S}$ profiles and kappa values, all of which could have been mapped into a rather cumbersome logic tree. The key point is that the final range of $V_{S}$-kappa adjustment factors captures the range of epistemic uncertainty implied by the possible combinations of these individual uncertainties. To avoid a computational penalty for the hazard calculations, it was decided to use a simple three-branch logic tree with different adjustment factors computed from a wide range of target kappa values. Application of these three factors transformed the three selected backbone GMPEs into nine new equations. As explained in Bommer et al. (2014) these were then transformed into 36 equations through the application of scaling factors for host-to-target region differences. 

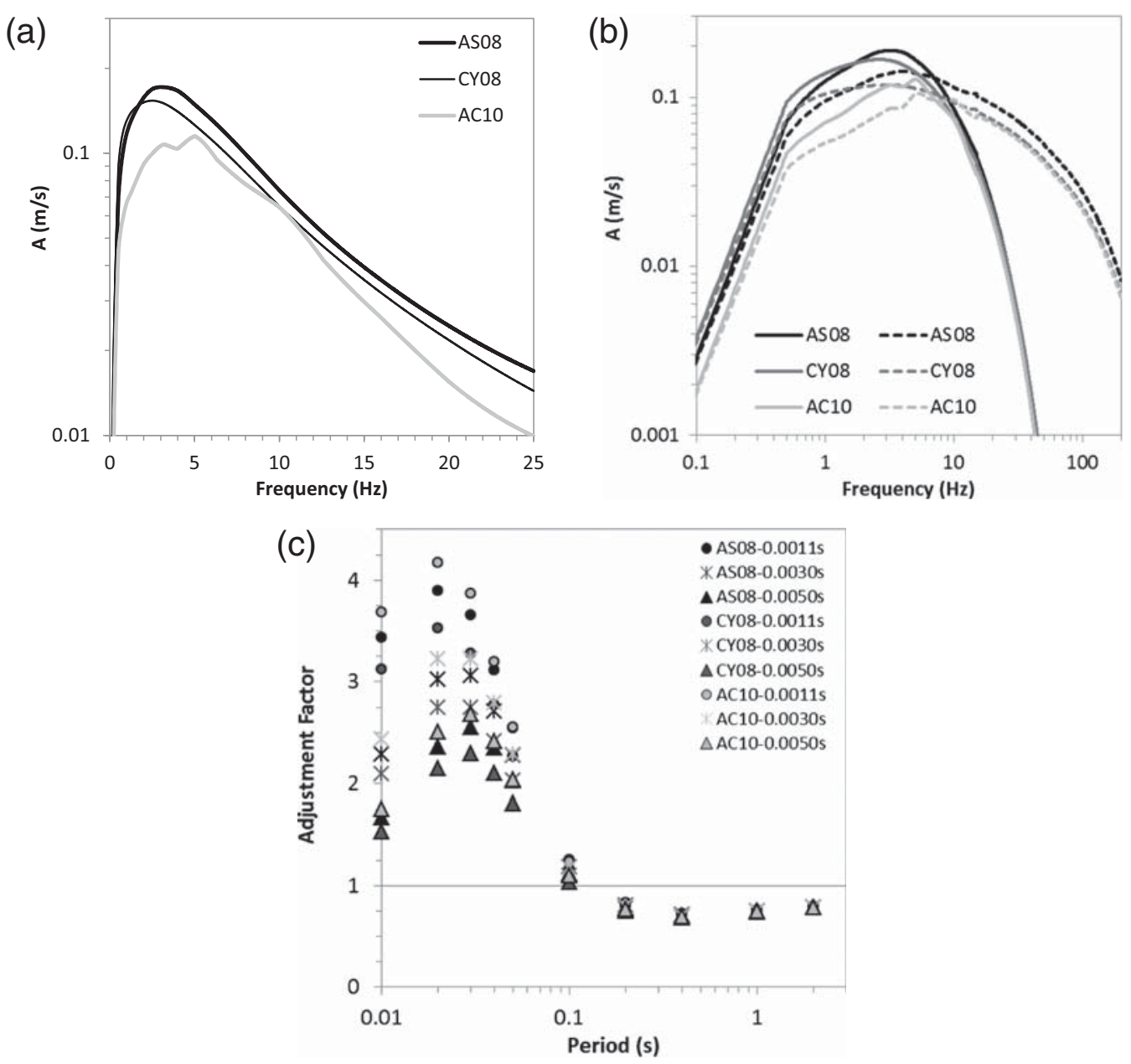

Figure 2. (a) Fourier amplitude spectra (FAS) derived from GMPEs and used to compute $\kappa_{0}$, (b) original and $V_{S}$-kappa adjusted FAS for $\kappa_{0}=0.0011 \mathrm{~s}$, and (c) $V_{S}$-kappa adjustment factors applied to median response spectral accelerations predicted by the three selected GMPEs using three target values for $\kappa_{0}$. AS08 is Abrahamson and Silva (2008), CY08 is Chiou and Youngs (2008), and AC10 is Akkar and Çağnan (2010).

Analyses were conducted to explore the sensitivity of anchoring the adjustments to a single magnitude and distance scenario by generating $V_{S}$-kappa adjustment factors for a wide range of magnitudes and distances. The results showed that for most scenarios (with larger magnitudes and at longer distances) the factors would be smaller (Fig. 3), hence it was concluded to be a conservative option to use adjustment factors developed for a single scenario and avoid the computational penalty of developing adjustment factors that vary with magnitude and distance.

Site-Response Model. The statistical models used to generate site properties for Thyspunt for the Monte Carlo simulations are described below, along with the development of the site amplification relationships.

Site Characterization. The Thyspunt site is underlain by Palaeozoic bedrock of the Table Mountain group that is part of the Cape fold belt. Four sedimentary formations are found across the site: the Peninsula, Cedarberg, Goudini, and
Skurweberg formations. The Peninsula and Skurweberg formations consist primarily of quartzitic sandstone, the Cedarberg formation consists of black shale, and the Goudini formation consists of finer grained quartzitic sandstone with some mudstone/shale and siltstone. The currently proposed site footprint of the nuclear island is located primarily within the Goudini formation (Fig. 4), with the Cedarberg and Peninsula formations to the north and the Skurweberg formation to the south along the coast.

The seismic site characterization for the Thyspunt site involved the measurement of the shear-wave velocity as a function of depth at multiple locations across the site. Two distinct field methods were used to measure shear-wave velocity: the multichannel analysis of surface waves (MASW) and $P S$ suspension logging. MASW testing was performed at six locations across the Thyspunt site, and PS suspension logging was performed at 29 locations during two phases of testing. The majority of the testing was performed within the Goudini formation, the geologic unit underlying the majority of the planned footprint of the Thyspunt facilities 

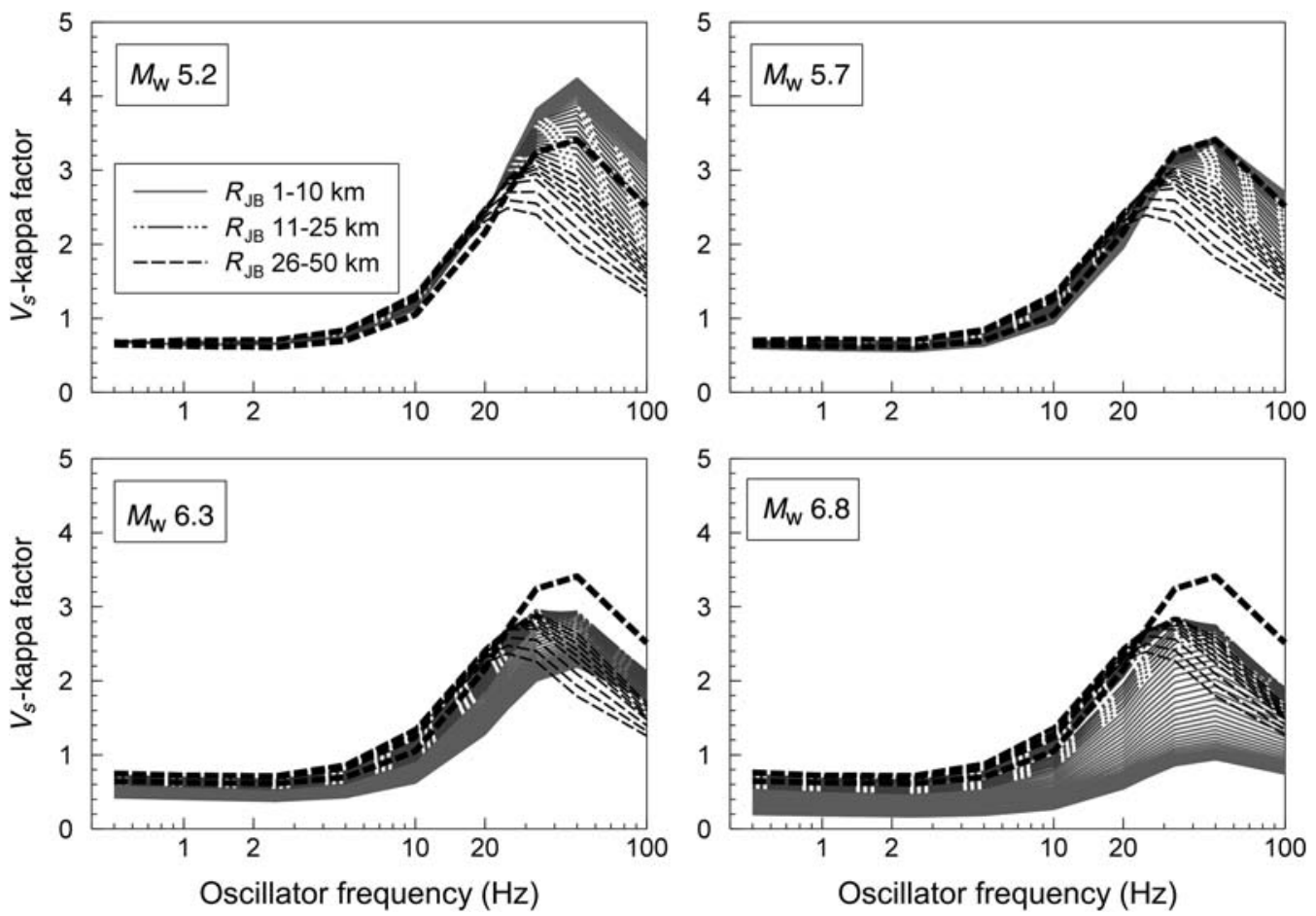

Figure 3. $V_{S}$-kappa adjustments from California to South Africa (with a target $\kappa_{0}$ of $0.0028 \mathrm{~s}$ ) for four magnitudes and distances from 1 to $50 \mathrm{~km}$; the heavy black dashed line represents the $V_{S}$-kappa adjustments corresponding to $M_{\mathrm{w}} 5.7$ and $R_{\mathrm{JB}} 10.1 \mathrm{~km}$.

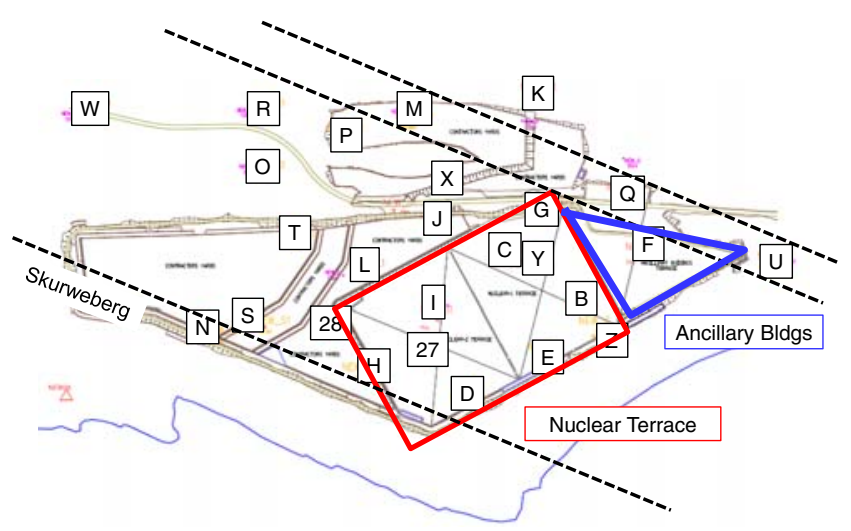

Figure 4. Thyspunt site with geologic formations and site characterization locations. Numbers and letters indicate boreholes in which shear-wave velocities were measured (Bommer et al., 2014). The color version of this figure is available only in the electronic edition.

(Fig. 4). The large number and spatial breadth of test locations across the site allowed the site characterization to cover any potential relocation or expansion of the nuclear island. A substantial layer of sand overlies much of the site. This layer is absent along the southern coastline, but inland it ranges from a few meters to more than $20 \mathrm{~m}$ thick. The presence of the thick sand cover at the site led to low resolution in the MASW results at the depths of interest. For this reason, the $V_{S}$ model was developed using only the $P S$ suspension logging results.
PS suspension logging is a borehole technique that measures the shear- and compression-wave velocity of the material adjacent to the borehole wall. The $P S$ suspension logging method directly measures the shear-wave velocity at different depths using travel-time measurements between locations a known distance apart. Testing was performed in 21 boreholes located on the Goudini formation, 4 boreholes on the Cedarberg formation, 3 boreholes on the Skurweberg formation, and 1 borehole on the Peninsula formation. The Skurweberg and Peninsula formations are stiffer than the Goudini formation and thus not representative of the material underlying the footprint of the planned facilities. Twenty-six shear-wave velocity profiles measured by $P S$ logging within the Goudini and Cedarberg formations are plotted together in Figure 5a. All velocity profiles are plotted with respect to the top of rock, as identified in the borehole at the base of the sand layer. The average velocity profile starts at about $1200 \mathrm{~m} / \mathrm{s}$ at the top of rock and linearly increases to about $3000 \mathrm{~m} / \mathrm{s}$ at $60 \mathrm{~m}$ depth.

There is considerable variability between the individual velocity profiles. Systematic spatial variability among the velocity profiles was investigated; however, no trends were observed, so the data were analyzed together. Figure $5 \mathrm{~b}$ plots the standard deviation of the natural logarithm of the $V_{S}$ data $\left(\sigma_{\ln V_{S}}\right)$ as a function of depth. The standard deviation is only shown over depths for which there are three or more measurements of shear-wave velocity. Generally, $\sigma_{\ln V_{S}}$ decreases with depth; values are between 0.2 and 0.3 near the surface and approach 0.1 at depth. The variability increases at depths 

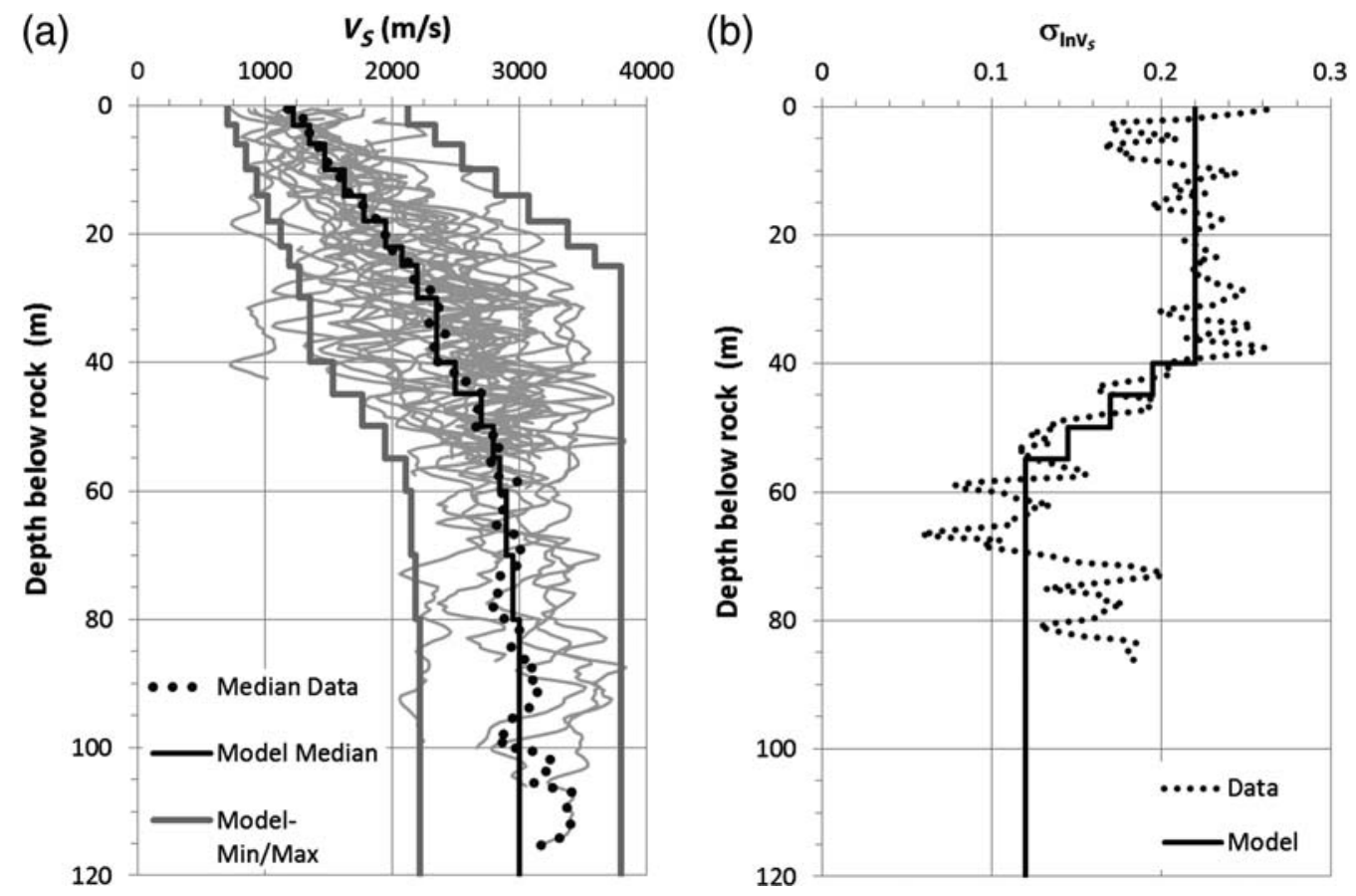

Figure 5. Site-specific shear-wave velocity model for the Thyspunt site: (a) median shear-wave velocity profile and (b) $\sigma_{\ln } V_{S}$ profile.

greater than about $70 \mathrm{~m}$, but this apparent increase is most likely caused by the reduction in the number of velocity profiles at these depths coupled with the smaller shear-wave velocities (i.e., $\sim 2000 \mathrm{~m} / \mathrm{s}$ ) measured in one borehole at these depths (Fig. 5a).

The shear-wave velocity data in Figure 5 were used to develop site-specific statistical models for the generation of shear-wave velocity profiles for Monte Carlo simulation. The statistical generation of shear-wave velocity profiles involves a layering model and a velocity model. The layering model describes the variation of layer thickness (or layer transition rate) and is used to generate the thicknesses of layers within a simulated velocity profile. The velocity model describes the statistical variation of shear-wave velocity within each layer and is used to assign velocities to the layers in the simulated profile.

The layering model is based on the model developed by Toro (1995), which is a nonhomogenous Poisson model in which the average layer transition rate $\left(\lambda_{t}\right)$ is depth dependent. The average layer transition rate represents the number of layer boundaries per meter, and its inverse is analogous to the average layer thickness. To develop the layering model, each $V_{S}$ profile was discretized into layers of constant slowness (i.e., reciprocal of $V_{S}$ ) based on visual inspection of the slowness profile. Slowness was used rather than shear-wave velocity because slowness emphasizes lower velocity layers, which more strongly influence site amplification. The observed number of layer transitions within $10 \mathrm{~m}$ bins was used to compute the average transition rate as a function of depth (Fig. 6a). The exponential functional form proposed by Toro (1995) was fit to the data and is also shown in Figure 6a. The model indicates $\lambda_{t}$ equal to $0.3 \mathrm{~m}^{-1}$ near the surface (i.e., average layer thickness of about $3 \mathrm{~m}$ ) and $\lambda_{t}$ equal to $0.11 \mathrm{~m}^{-1}$ at a depth of $80 \mathrm{~m}$ (i.e., thickness about $9 \mathrm{~m}$ ). The generic layering model developed by Toro (1995), which generally displays smaller $\lambda_{t}$ (i.e., thicker layers) than the Thyspunt data at all depths is also shown in Figure 6a. This difference is attributed to the fact that the Toro (1995) model is based on $V_{S}$ profiles at predominantly soil sites, whereas the Thyspunt site is a rock site.

For each simulated shear-wave velocity profile, the layer thicknesses are generated using the layering model and then velocities are assigned to these layers. Assuming a lognormal distribution for shear-wave velocity, the shear-wave velocity of a layer is derived from the median $V_{S}$ at mid-depth of that layer (Fig. 5a), the standard deviation of the natural logarithm of $V_{S}$ at mid-depth of that layer (Fig. 5b), and an interlayer correlation coefficient $\rho$ (Toro, 1995).

The interlayer correlation model for Thyspunt was developed by first computing the normalized residual $(\varepsilon)$ of the natural logarithm of $V_{S}$ in each layer and then calculating the correlation coefficient between $\varepsilon$ values from adjacent layers. Toro (1995) developed a model for the interlayer correlation coefficient that is dependent on depth and the distance between the midpoint of adjacent layers. To investigate the influence of depth $(d)$ and interlayer separation distance (th) on the Thyspunt data, $\rho$ was computed for $\varepsilon$ values in different bins of $d$ and $t h$ with bin widths of $\Delta d$ and $\Delta t h$, respectively. Bins are required such that enough data pairs are available to compute $\rho$. Values of $\Delta d$ between 5 and $20 \mathrm{~m}$, and values of $\Delta t h$ between 1 and $9 \mathrm{~m}$ were considered; $\rho$ was computed for bins that contained at least 10 pairs of $\varepsilon$. 

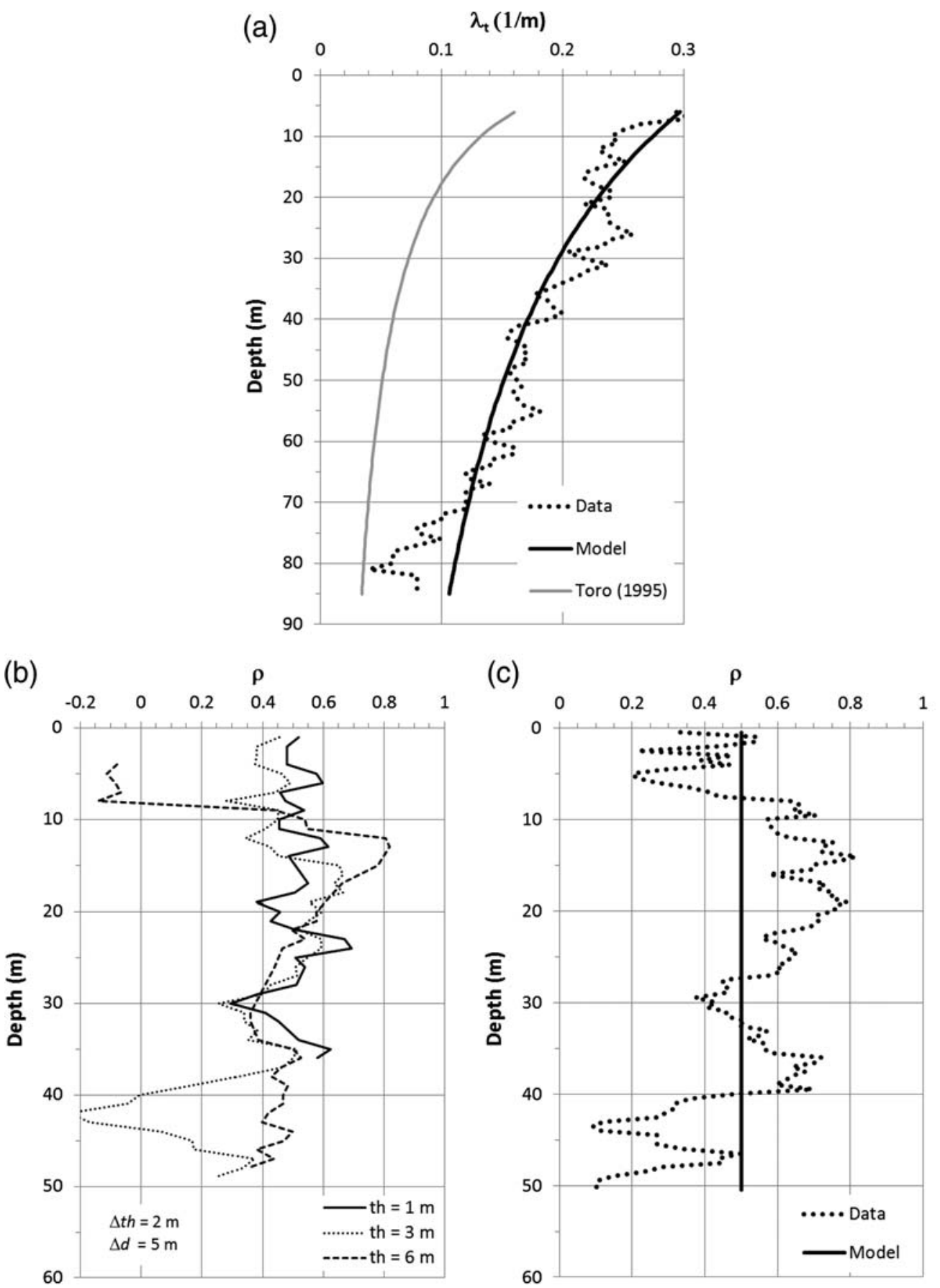

Figure 6. Site-specific layering model developed for the Thyspunt site.

Figure $6 \mathrm{~b}$ plots computed $\rho$ values versus depth for different values of th using bin widths of $\Delta t h=2 \mathrm{~m}$ and $\Delta d=5 \mathrm{~m}$. The influence of $t h$ is not strong, which suggests a correlation model that is independent of interlayer separation. Figure $6 \mathrm{c}$ shows the computed $\rho$ values versus depth in which $\rho$ is computed using all pairs of adjacent layers using $\Delta d=1 \mathrm{~m}$. There is no systematic variation of $\rho$ with depth, and thus an average $\rho$ value of 0.5 was used.

To illustrate the velocity profiles generated using the models described, a subset of 10 shear-wave velocity profiles are plotted versus depth in Figure 7. These 10 realizations show that the layer thicknesses vary from profile to profile and the thickness generally increases with depth. The simulated profiles are located both above and below the median $V_{S}$ model, and a single profile may be above the median at some depths and below the median at others. One-hundred simulated velocity profiles were developed for the siteresponse analyses. Using 100 simulations, both the median velocity profile and the variation of $\sigma_{\ln V_{S}}$ with depth were captured by the Monte Carlo simulations 


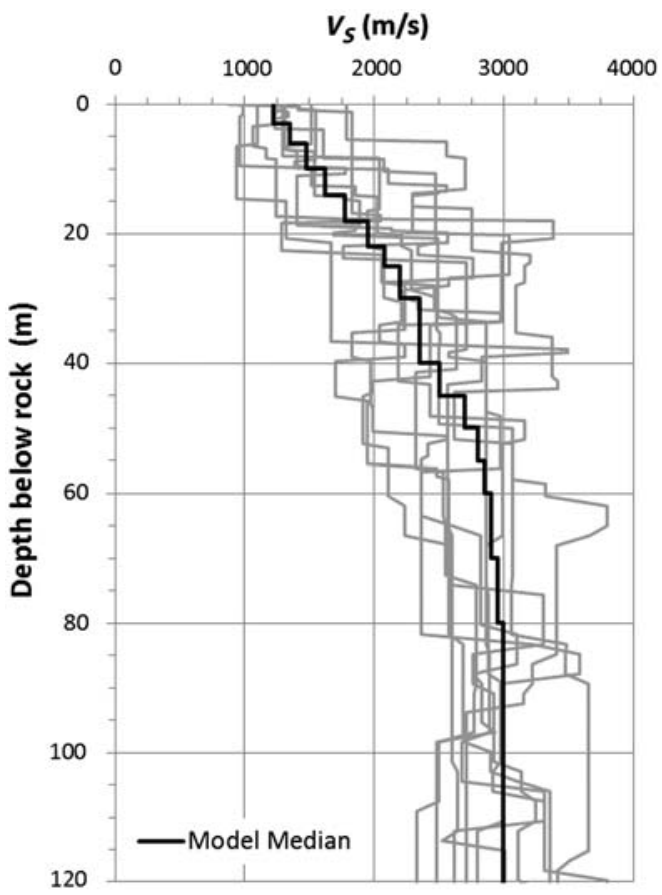

Figure 7. Examples of simulated shear-wave velocity profiles for the Thyspunt site.

The nonlinear properties of the rock describe the reduction in shear modulus $\left(G / G_{\max }\right)$ and the increase in damping ratio $(D)$ with shear strain. It is difficult to measure the nonlinear properties of fractured rock in the laboratory because of the influence of discontinuities and jointing on the results, and therefore no dynamic laboratory testing was performed on rock cores from the site. However, relevant studies from the literature were identified to inform the selection of the nonlinear rock properties.

Most of the published laboratory studies on rock focus on measuring the small-strain shear modulus $\left(G_{\max }\right)$ and small-strain damping ratio $\left(D_{\min }\right)$ rather than the variation of these properties with shear strain. One notable exception is Choi (2008), a study that measured the modulus reduction and damping curves of welded volcanic tuff formations from Nevada and New Mexico. Although volcanic tuff formations are different from the sedimentary formations at Thyspunt, the measured shear-wave velocities of the tuff specimens are similar to those measured at Thyspunt and are considered applicable to the sedimentary units at Thyspunt. An additional source of information regarding the nonlinear properties of rock is Schnabel (1973). These properties are shown in Figure 8 along with the range of values reported by Choi (2008). The Schnabel (1973) curves generally are consistent with the range reported by Choi (2008) and thus are used as the basis for the curves used in the analyses for Thyspunt. However, the original Schnabel (1973) damping curve is adjusted to larger damping values based on the highly weathered and fractured nature of the rock at Thyspunt and the observed increase in damping due to cracking reported by Choi (2008).
The Darendeli and Stokoe (2001) models for nonlinear property variability are used for the Monte Carlo simulations. The Darendeli and Stokoe (2001) model assumes that the parameters $G / G_{\max }$ and $D$ are normally distributed at each strain level and that the standard deviation for each is a function of the magnitude of $G / G_{\max }$ and $D$, respectively. To avoid the simulation of unphysical $G / G_{\max }$ and $D$ values, the normal distributions were truncated at 0.05 and 1.0 for $G / G_{\max }$ and $0.1 \%$ and $15 \%$ for $D$. A correlation coefficient of -0.5 was used to model the negative correlation between the $G / G_{\max }$ and $D$ curves.

Site-Response Analyses. The site-response analyses were performed using the program Strata (Kottke and Rathje, 2008). The program Strata performs 1D equivalent-linear siteresponse analysis in which the nonlinear response of the soil and rock is modeled through strain-compatible properties. The site response can be computed using either input time series or the RVT approach (e.g., Silva et al., 1997; Rathje and Ozbey, 2006). The RVT approach was used in this project because the input excitation can be defined from a response spectrum using inverse RVT (e.g., Rathje et al., 2005), which avoids the need of generating time-domain input motions and also results in a significant reduction in computational costs. Strata also allows users to perform Monte Carlo simulations that statistically vary the site layering, the shear wave associated with each layer, and the nonlinear properties.

The input motions for the site-response analyses were developed from the UHS for the reference rock condition. Scenario spectra fit to the high-frequency (HF) and lowfrequency (LF) portions of the UHS were generated for three hazard levels (annual frequencies of exceedance equal to $10^{-4}, 10^{-5}$, and $10^{-6}$ ) resulting in six different input response spectra. The HF spectra were developed from the magnitude and distance disaggregations at $5-10 \mathrm{~Hz}$ and the LF spectra from the magnitude and distance disaggregations at $1-2.5 \mathrm{~Hz}$. For the HF spectra a GMPE-computed response spectrum for the $\mathrm{M}, \mathrm{R}$ scenario was scaled to the UHS at a frequency of $7.5 \mathrm{~Hz}$, and for the LF spectra the GMPE-computed response spectrum was scaled to the UHS at a frequency of $1.75 \mathrm{~Hz}$. To account for the different GMPEs and the different $V_{S}$-kappa corrections, the GMPE-computed response spectra were weighted response spectra computed from the nine GMPEs developed as part of this project (i.e., three backbone GMPEs times the three $V_{S}$-kappa corrections).

The resulting HF and LF scenario spectra are plotted in Figure 9; the intensity of these spectra spans about one order of magnitude. A suite of input motions associated with only three hazard levels was deemed sufficient for the Thyspunt site because it is very stiff and the AFs will not vary significantly with $\mathrm{Sa}_{\mathrm{r}}$. For each input motion, 100 Monte Carlo simulations were performed on the site properties (i.e., shear-wave velocity profile and nonlinear property curves).

The AFs computed from the $10^{-5} \mathrm{LF}$ scenario spectrum are plotted in Figure 10a. The median AF indicates amplification of about $1.2-1.5$ at periods less than $0.25 \mathrm{~s}$, with 

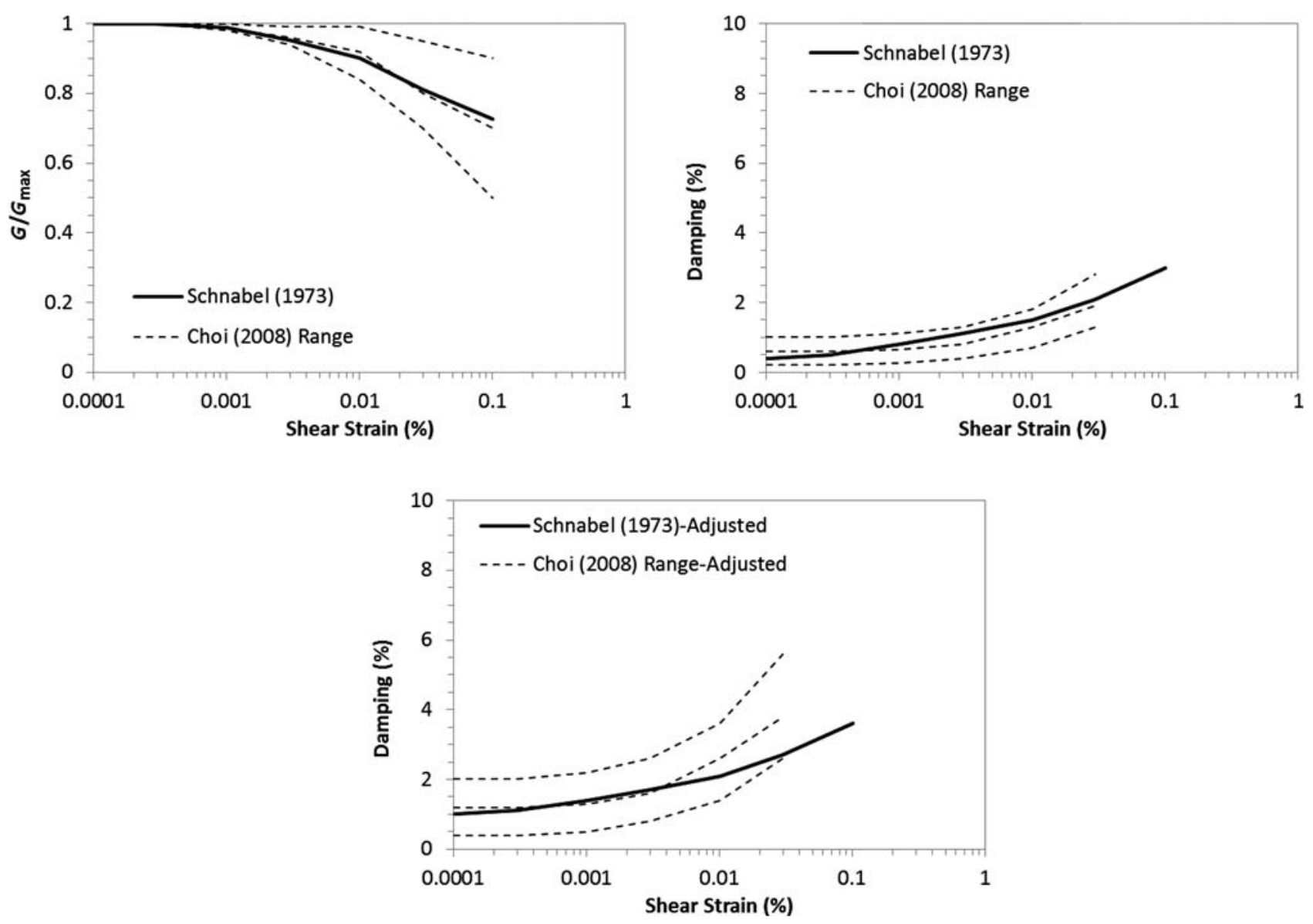

Figure 8. Modulus reduction and damping curves for rock from Schnabel (1973) and Choi (2008).

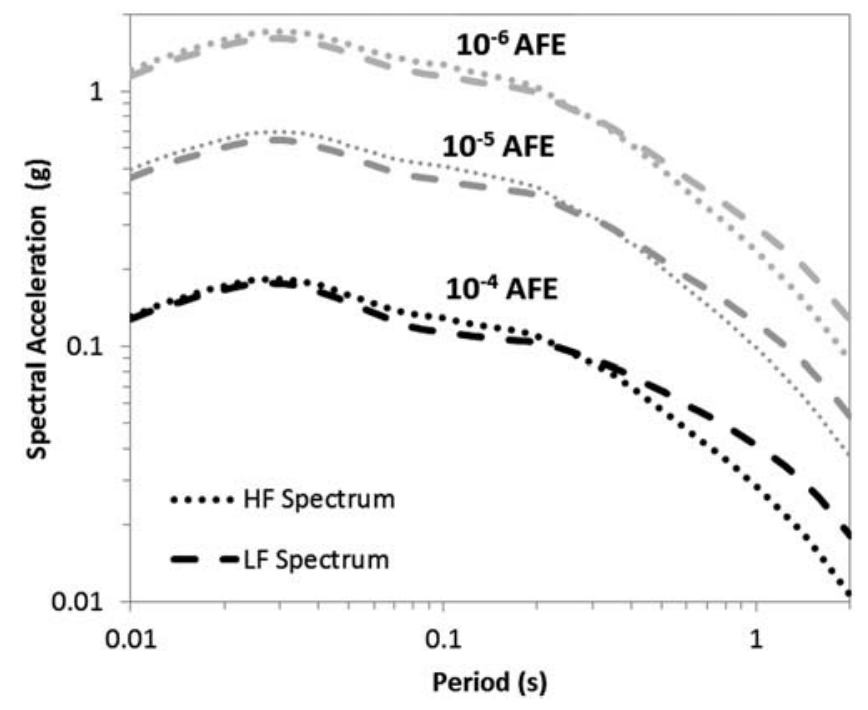

Figure 9. Scenario spectra used as input into the site-response analyses. (AFE, annual frequency of exceedance; HF, high frequency; LF, low frequency.)

decreasing values of AF toward 1.0 at periods greater than $0.25 \mathrm{~s}$. There is variability in the computed AF because of the variability in the site properties modeled through the Monte Carlo simulations. This variability is largest at periods less than $0.1 \mathrm{~s}$. The standard deviation of the natural logarithm of AF $\left(\sigma_{\ln \mathrm{AF}}\right)$ is plotted in Figure $10 \mathrm{~b}$. The $\sigma_{\ln \mathrm{AF}}$ varies from about 0.2 at short periods to close to 0.0 at periods greater than $1.0 \mathrm{~s}$.

The site-response results were used to develop AF relationships that describe the variation of $\mathrm{AF}$ with input $\mathrm{Sa}_{\mathrm{r}}$ and provide an associated $\sigma_{\ln \text { AF }}$. Figure 11 plots the computed AF data versus $\mathrm{Sa}_{\mathrm{r}}$ for four representative periods. The large stiffness of the site results in a very minor $\mathrm{Sa}_{\mathrm{r}}$ dependence for AF. A linear relationship was fit between the natural logarithm of $\mathrm{AF}$ and the natural logarithm of $\mathrm{Sa}_{\mathrm{r}}$ to model the median AF. An associated $\sigma_{\ln \mathrm{AF}}$ was computed for each period (Fig. 12).

Epistemic modeling uncertainty, defined by Toro et al. (1997) as the uncertainty in the true bias of a model, is associated with all types of site-response models used in engineering seismology. One-dimensional site-response analysis does not capture all aspects of wave propagation at a site, and this issue potentially results in a bias with respect to the true site amplification. Currently, there are no published estimates of the uncertainty in the bias of site amplification estimates. Therefore, an analysis of a small set of Japanese KiK-net borehole array sites was used to inform the selection of this epistemic uncertainty. The mean bias between 
(a)

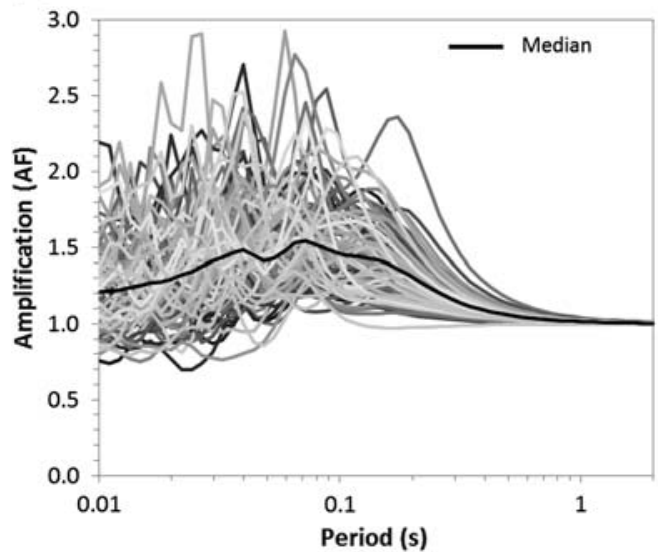

(b)

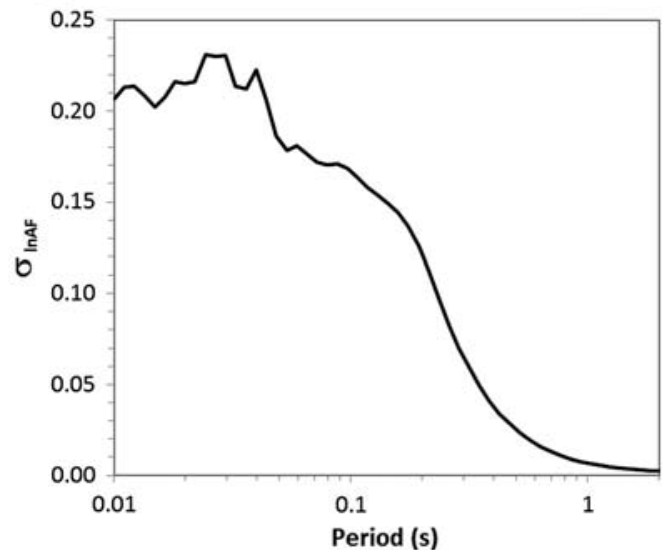

Figure 10. (a) Computed amplification factors (AFs) for 100 Monte Carlo simulations for a single-input motion spectrum, and (b) standard deviation of the natural logarithm of $\mathrm{AF}\left(\sigma_{\ln \mathrm{AF}}\right)$. The input motion for these analyses is the $10^{-5} \mathrm{LF}$ spectrum (Fig. 8).
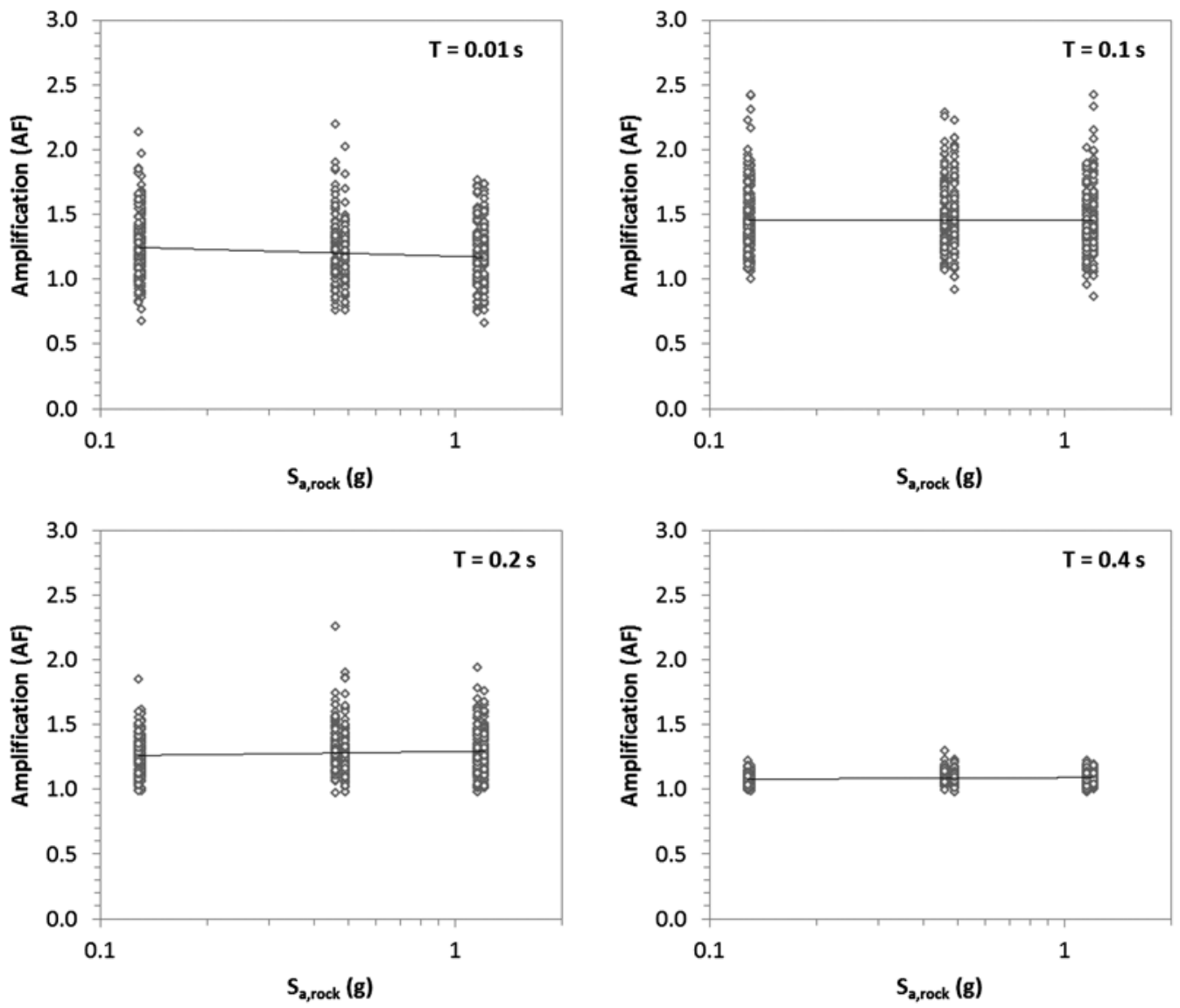

Figure 11. Amplification versus $\mathrm{Sa}_{\mathrm{r}}$ for $T=0.01,0.1,0.2$, and $0.4 \mathrm{~s}$.

predicted equivalent-linear AFs and recorded AFs was computed for nine KiK-net soil sites. The standard deviation of the mean bias values across the nine sites $\left(\sigma_{\mu}\right)$ is a measure of the epistemic uncertainty associated with the $1 \mathrm{D}$ equivalent linear analyses at those sites. The computed $\sigma_{\mu}$ was about 0.15 at short periods, increased to about 0.4 for periods between 0.1 and $0.5 \mathrm{~s}$, and decreased toward 0.25 at a period of $2.0 \mathrm{~s}$.

Because the Thyspunt site is a rock site and the levels of site amplification are relatively small, it is expected that $\sigma_{\mu}$ is smaller than those for soil sites. In addition, because the site 


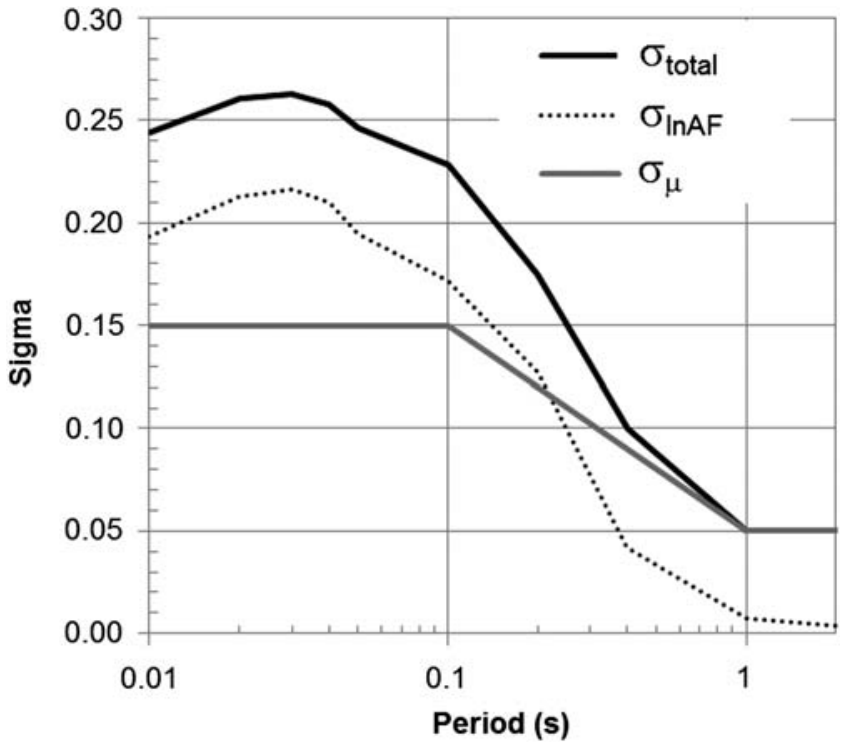

Figure 12. Period dependence of $\sigma_{\ln \mathrm{AF}}, \sigma_{\mu}$, and $\sigma_{\text {total }}$ for the site-response model. $\sigma_{\ln \mathrm{AF}}$ represents the variability in $\mathrm{AF}$ from the $1 \mathrm{D}$ site-response modeling, $\sigma_{\mu}$ represents the epistemic uncertainty in mean estimates of AF from 1D site-response modeling, and $\sigma_{\text {total }}$ is the square root of the sum of the squares of $\sigma_{\ln \mathrm{AF}}$ and $\sigma_{\mu}$.

amplification approaches 1.0 at longer periods (Fig. 10a), $\sigma_{\mu}$ is expected to decrease with increasing period. Using this reasoning $\sigma_{\mu}$ was taken as 0.15 at periods less than $0.1 \mathrm{~s}$ and decreasing to 0.05 at periods greater than $1.0 \mathrm{~s}$ (Fig. 12). The values of $\sigma_{\mu}$ are combined with the $\sigma_{\ln \mathrm{AF}}$ values using the square root of the sum of the squares to generate a total standard deviation $\left(\sigma_{\text {total }}\right)$ that is used in the convolution calculations (Fig. 12).

Sigma Model. A partially nonergodic sigma model was adopted for the Thyspunt PSHA. The requirements for adoption of this model were satisfied because a site-specific $V_{S}$-kappa correction was applied to the backbone GMPEs and because site-response calculations were performed. The epistemic uncertainty in the site term was taken into account through the use of branches in the median logic tree for the $V_{S}$-kappa correction factors (Fig. 2c) and by the inclusion of variability in the site AFs from the geotechnical site-response analyses (Fig. 10b). The requirement that the epistemic uncertainty in the single-station sigma be included was satisfied by incorporating a sigma logic tree that represents the epistemic uncertainty in the sigma model.

One of the motivating factors for adopting a partially nonergodic approach is to avoid double-counting uncertainty. Double counting occurs when the modifications to the backbone GMPE that are meant to correct for site-specific effects (e.g., the $V_{S}$-kappa correction and the site-response calculations) introduce epistemic uncertainty, and this uncertainty is also included in sigma through the site-to-site variability ( $\phi_{S 2 S}$ in equation 3$)$. Therefore, the partially nonergodic approach ignores $\phi_{S 2 S}$ (equation 4). However, at

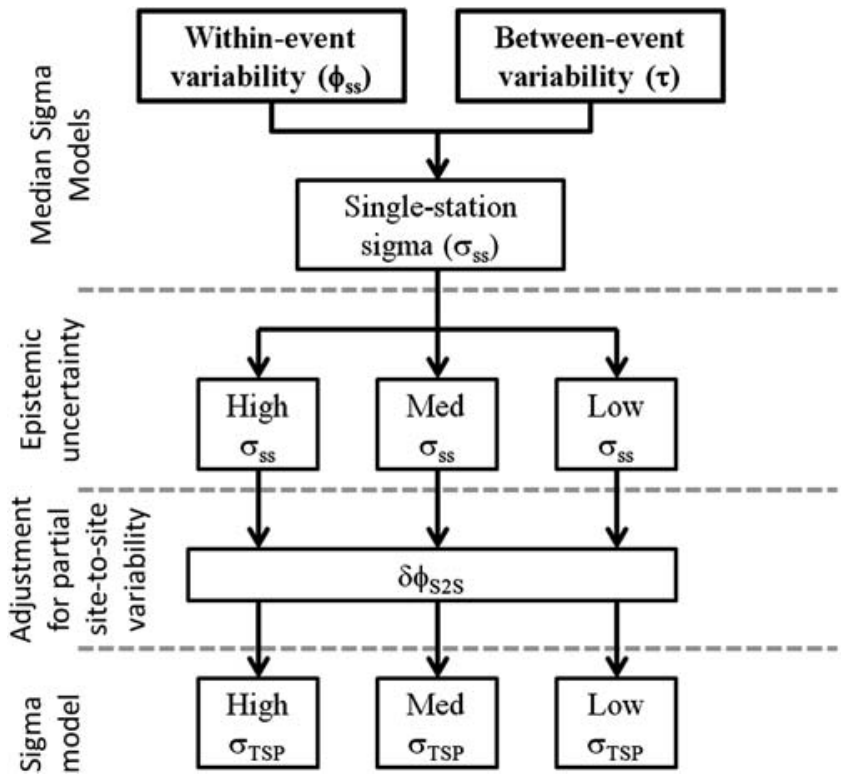

Figure 13. Schematic representation of the sigma model. The top two boxes (in bold) have alternative homoskedastic and heteroskedastic models.

long periods the range of adjustment factors for the $V_{S}$-kappa corrections (Fig. 2) and the variability in the site AFs (Fig. 10b) is small, and therefore this approach may underestimate the epistemic uncertainty in the site term at long periods. For this reason, a partial site-to-site variability term $\left(\delta \phi_{S 2 S}\right)$ was included in the sigma model. The sigma model becomes

$$
\sigma_{\mathrm{TSP}}=\sqrt{\tau^{2}+\phi_{s s}^{2}+\left(\delta \phi_{S 2 S}\right)^{2}}
$$

in which $\sigma_{\mathrm{TSP}}$ denotes the sigma used for the hazard analyses at the Thyspunt site and $\delta \phi_{S 2 S}$ is a correction to the pure single-station sigma model (i.e., equation 4) to account for the fact that the full epistemic uncertainty in the site term may not be accounted for by the various logic-tree branches for the median ground-motion model and the convolution calculation. This approach introduces a measure of epistemic uncertainty $\left(\delta \phi_{S 2 S}\right)$ into the aleatoric standard deviation. Although this mixture of epistemic and aleatory uncertainty generally is undesired, this approach is common to most past PSHA studies in which the uncertainty in the site term (i.e., the site-to-site variability, $\phi_{S 2 S}$ ) has always been included in the total (ergodic) standard deviation.

A schematic representation of the sigma model is shown in Figure 13. The median sigma models were built from the components in equation (7): $\phi_{s s}, \tau$, and $\delta \phi_{S 2 S}$. Two median sigma models were considered for the sigma logic tree: a magnitude-independent (homoskedastic) model and a magnitude-dependent (heteroskedastic) model. The two models represent the differing views in the scientific community on the magnitude dependency of sigma. Moreover, the two models represent a trade-off between simplicity (i.e., 

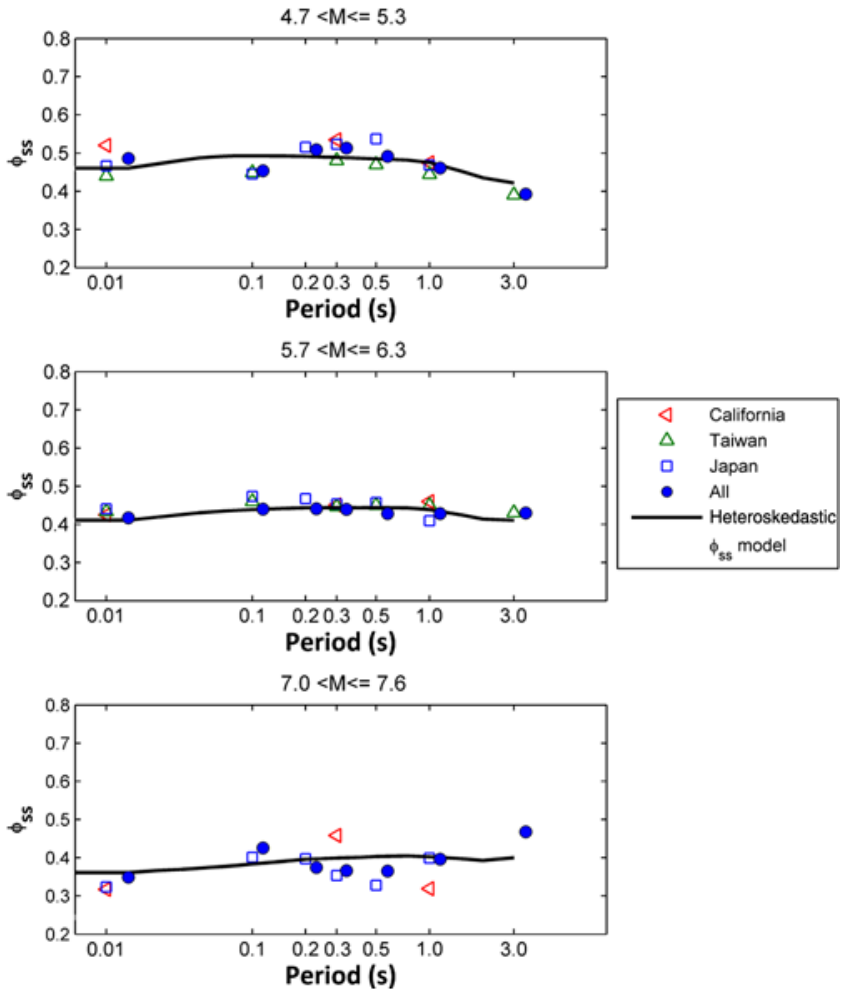

Figure 14. $\phi_{s s}$ values obtained by fitting the magnitude-dependent model to the PEGASOS Refinement Project (PRP) residuals for different magnitude bins $(R \leq 200 \mathrm{~km})$. Results are shown separately for data from three regions, as well as the regions combined. The heteroskedastic $\phi_{s s}$ model is shown for the magnitude corresponding to the center of the magnitude bin. The color version of this figure is available only in the electronic edition.

constant sigma) and an ability to properly constrain the values of sigma for a magnitude-dependent model. In the sigma logic tree, we gave a higher weight (0.6) to the heteroskedastic model branch than to the homoskedastic model branch (0.4). The following section describes the development of the median branches for $\phi_{s s}, \tau$, and $\delta \phi_{S 2 S}$ for the homoskedastic and heteroskedastic models.

Median Models for $\phi_{s s}, \tau$, and $\delta \phi_{S 2 S}$. The median $\phi_{s s}$ model was constrained using a worldwide database compiled for the PEGASOS Refinement Project (PRP; Renault et al., 2010). This database is composed of ground-motion records from California, Switzerland, Taiwan, Turkey, and Japan. Most of the records, however, come from California, Taiwan, and Japan. The residuals in the database were partitioned according to equation (2) using a random effects regression. Details on the database and the regression methodology are given in Rodriguez-Marek et al. (2013).

The $\delta W S_{e s}$ residuals in the PRP database indicate a magnitude dependency for $\phi_{s s}$ similar to that observed in some ergodic $\phi$ models (e.g., Abrahamson and Silva, 2008; Chiou and Youngs, 2008), in which $\phi_{s s}$ values decrease with increasing magnitude. Rodriguez-Marek et al. (2013) also investigated a distance-dependent model for $\phi_{s s}$; however,

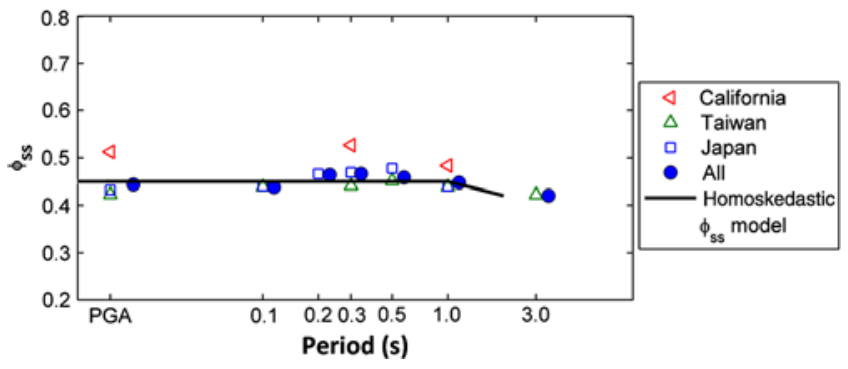

Figure 15. Magnitude-independent $\phi_{s s}$ values obtained using residuals from the PRP database for data from three regions and the regions combined. Also shown is the homoskedastic $\phi_{s s}$ model. The color version of this figure is available only in the electronic edition.

a clear distance dependence was not observed when considering only earthquakes with magnitude 5 and above. Because the Thyspunt PSHA was conducted using a minimum magnitude threshold of 5 in accordance with RG 1.208 (USNRC, 2007), the $\phi_{s s}$ models for Thyspunt were magnitude dependent but distance independent.

The heteroskedastic median $\phi_{s s}$ model was obtained by performing a maximum likelihood regression on the $\delta W S_{e s}$ residuals of the PRP database using the same functional form for magnitude dependence as AS08 and CY10. Figure 14 shows the regression results for $\phi_{s s}$ for three magnitude bins. The regression results are shown separately for the California, Taiwan, and Japan regions, as well as the three regions combined. The $\phi_{s s}$ data from the three regions are consistent with each other, which supports combining the data across regions. The period dependence of $\phi_{s s}$ is modest and is in part controlled by the fact that the number of records in the PRP database varies significantly across periods. To provide a natural interpolation across periods, while reproducing the PRP $\phi_{s s}$ values and their magnitude dependency, the heteroskedastic median $\phi_{s s}$ model was developed by scaling the $\phi$ model from a GMPE to match the data in Figure 14. The final heteroskedastic median $\phi_{s s}$ model is the $\phi$ model from the AS08 GMPE scaled by a factor of 0.8. This factor was obtained by minimizing the difference between the PRP residuals and the scaled AS08 $\phi$ (the AS08 $\phi$ value was computed with the measured $V_{S 30}$ flag and for a $V_{S 30}$ value larger than $V_{\text {LIN }}$ to avoid effects of nonlinearity). Observe that the scaled AS08 $\phi$ is a very good fit to the $\phi_{s s}$ values (Fig. 14).

The homoskedastic median $\phi_{s s}$ model was obtained from the standard deviation of $\delta W S_{e s}$ from events with magnitude greater than 5.0 and distance less than $200 \mathrm{~km}$ (Fig. 15). The variation of $\phi_{s s}$ with oscillator period was not significant, hence a period-independent $\phi_{s s}$ model was selected. A value of $\phi_{s s}=0.45$ was adopted. However, the value of $\phi_{s s}$ at $T=2.0 \mathrm{~s}$ was reduced so that the crossover between the total homoskedastic and heteroskedastic sigma models occurred always at $M_{\mathrm{w}} 5.7$ (without an adjustment, this crossover occurred at this magnitude for all periods except $T=2.0 \mathrm{~s}$ ). The proposed homoskedastic median $\phi_{s s}$ 


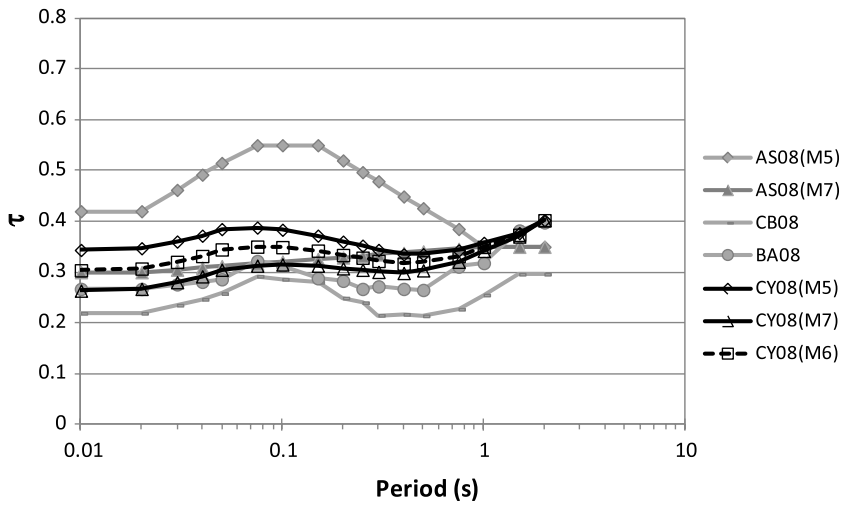

Figure 16. NGA $\tau$ models (AS08, Abrahamson and Silva, 2008; CB08, Campbell and Bozorgnia, 2008; BA08, Boore and Atkinson, 2008; and CY08, Chiou and Youngs, 2008). CY08 was selected as the heteroskedastic $\tau$ model, and CY08(M6) was selected as the homoskedastic $\tau$ model.

model is consistent with previously published data (Atkinson, 2006; Lin et al., 2011).

The median $\tau$ model was selected from between-event variability models in existing GMPEs. Figure 16 shows the $\tau$ values from the Next Generation Attenuation (NGA) models, which are deemed to be well constrained. The CY08 $\tau$ values are in the midrange of all the other NGA models. For this reason, the CY08 $\tau$ model was selected as the heteroskedastic median $\tau$ model. For the homoskedastic model, the values at the midrange between the high $\tau$ at low magnitudes and the low $\tau$ at large magnitudes were selected as the median model. These values correspond to the CY08 model for a magnitude of 6.0.

To evaluate the partial site-to-site variability $\left(\delta \phi_{S 2 S}\right)$ required at long periods, the equivalent variability associated with the $V_{S}$-kappa correction and site-response calculations is considered along with a minimum level of epistemic uncertainty for the site term. The variability introduced by the $V_{S}$-kappa correction can be computed by obtaining the standard deviation of the natural logarithms of the weighted $V_{S}$-kappa adjustment factors $\left(\sigma_{V_{S}}\right)$. The computed values of $\sigma_{V_{S} \kappa}$ vary across period, as shown in Figure 17. The variability introduced by the site-response calculations was taken as the standard deviation of the site $\mathrm{AFs}\left(\sigma_{\ln \mathrm{AF}}\right)$. This standard deviation was computed from a preliminary set of site-response calculations and is also shown in Figure 17. Because the site response at the Thyspunt site is linear, the two sources of uncertainty can be combined using

$$
\sigma_{\text {epi,site }}=\sqrt{\sigma_{V_{S} \kappa}^{2}+\sigma_{\ln \mathrm{AF}}^{2}}
$$

in which $\sigma_{\text {epi,site }}$ represents the epistemic uncertainty for the site term. The resulting $\sigma_{\text {epi,site }}$ (Fig. 17) is very small at periods greater than about $0.3 \mathrm{~s}$. The $\delta \phi_{S 2 S}$ values were selected such that the combination of $\sigma_{\text {epi,site }}$ and $\delta \phi_{S 2 S}$ is larger than a minimum target value $\left(\sigma_{\text {epi,min }}\right)$ at all periods.

The choice for this target value $\left(\sigma_{\text {epi,min }}\right)$ was informed by observations from the KiK-net database. The KiK-net database has recordings at the surface and at depth, with most

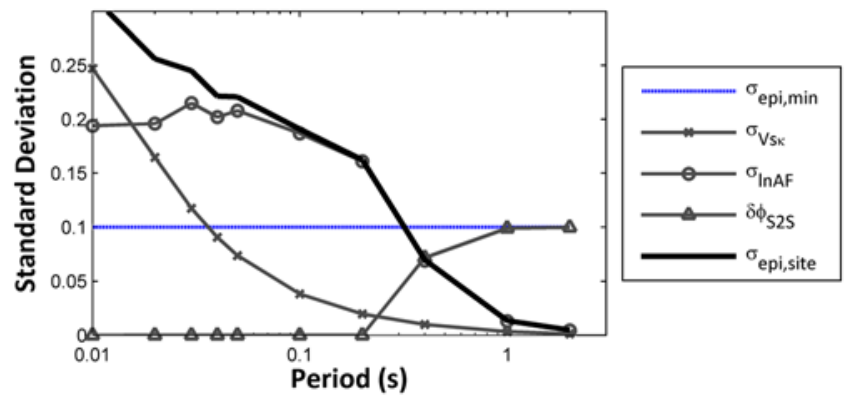

Figure 17. Different components of the epistemic standard deviation for the site term. $\sigma_{V_{S} \kappa}$ is the standard deviation implicit in the median logic-tree branches for the $V_{S}$-kappa correction. $\sigma_{\ln \mathrm{AF}}$ is a preliminary estimate of the standard deviation of the site amplification function. $\sigma_{\text {epi,min }}$ is the target value for the minimum epistemic uncertainty. $\delta \phi_{S 2 S}$ is the partial site-to-site variability correction. The color version of this figure is available only in the electronic edition.

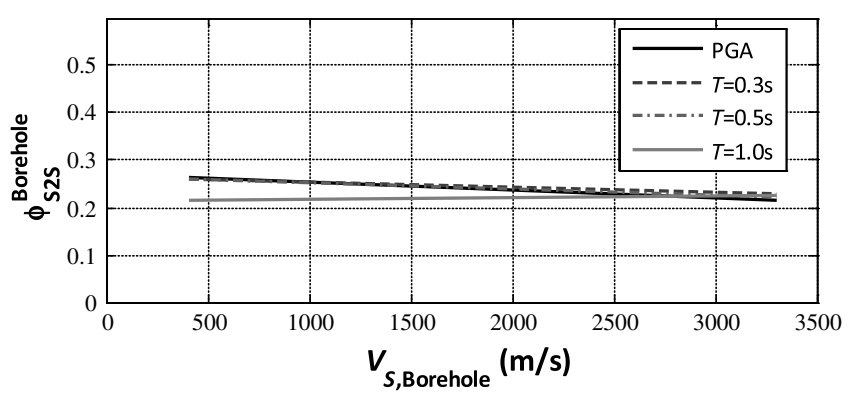

Figure 18. Site-to-site variability at borehole depth as a function of the shear-wave velocity at the borehole level from the KiKnet data for selected oscillator periods. The standard deviations are computed by postulating a linear standard deviation model and performing a maximum-likelihood regression.

of the at-depth instruments embedded in bedrock at depths of 100 or $200 \mathrm{~m}$ below the surface. The at-depth instruments allow for the quantification of the site-to-site variability at the borehole depth $\left(\phi_{S 2 S}^{B}\right)$, and the shear-wave velocities associated with these depths are analogous to the stiff Thyspunt site. Figure 18 plots $\phi_{S 2 S}^{B}$ as a function of shear-wave velocity at the borehole for four spectral periods. The site-to-site standard deviation at the borehole $\left(\phi_{S 2 S}^{B}\right)$ has a value of about 0.2 for all spectral periods. This value also appears to be independent of the shear-wave velocity at the borehole.

The selected target value for $\sigma_{\text {epi,min }}$ was 0.1 . This value reflects a balance between the observed site-to-site variability at the borehole in the KiK-net data $\left(\phi_{S 2 S}^{B}=0.2\right)$ and the zero epistemic uncertainty implied by the large stiffness of the Thyspunt site, which results in no site response or $V_{S}$-kappa effects at long periods. Hence, $\delta \phi_{S 2 S}$ was selected as the lowest value that would satisfy

$$
\sqrt{\sigma_{V_{S} \kappa}^{2}+\sigma_{\ln \mathrm{AF}}^{2}+\delta \phi_{S 2 S}^{2}} \geq 0.1
$$

The selected values of $\delta \phi_{S 2 S}$ are shown in Figure 17. 
Epistemic Uncertainty for the Sigma Model. The value of $\phi_{s s}$ at a given station is, in principle, a quantity that can be measured; hence its uncertainty is epistemic in nature. The quantification of this epistemic uncertainty is one of the requisites for the use of a single-station sigma approach (Requirement 3). In addition, the value adopted for $\tau$, by necessity, was imported from other regions and has its own epistemic uncertainty. No epistemic uncertainty for $\delta \phi_{S 2 S}$ was considered. The quantification of the epistemic uncertainty for $\phi_{s s}$ and $\tau$ is discussed below.

As discussed in the previous section, the median models for $\phi_{s s}$ were estimated from the PRP database because no recordings exist at the Thyspunt site. Similarly, the epistemic uncertainty for $\phi_{s s}$ can be estimated using the site-to-site variability of this parameter across sites from the PRP database. This is akin to adopting an ergodic approach on $\phi_{s s}$. The coefficient of variation for $\phi_{s s}$ (i.e., $\operatorname{std}\left(\phi_{s s}\right)$ divided by the expected value of $\phi_{s s}$ ) from sites from the PRP database is between 0.2 and 0.25 , but these values are estimated from a small number of sites and hence include statistical error. An estimate of the true coefficient of variation for $\phi_{s s}$ was obtained by generating large artificial datasets with known coefficients of variation and trying to match the observed coefficients of variation from the PRP database. The true coefficient of variation was estimated to be equal to 0.1 , and this results in $\operatorname{std}\left(\phi_{s s}\right)=0.1 \times \phi_{s s}$. This value was obtained assuming a homoskedastic model.

A similar exercise for the heteroskedastic model was not possible because there are not enough recordings to obtain estimates of the coefficient of variation for different magnitude ranges. However, with the exception of magnitude effects, the same factors that control the variability in $\phi_{s s}$ for the homoskedastic model also control this variability in the heteroskedastic model. Moreover, magnitude effects imply that the variability in $\phi_{s s}$ for the homoskedastic model is an upper bound to that of the heteroskedastic model. For these reasons, the estimates of the coefficient of variation for the homoskedastic model were applied to the heteroskedastic model as well.

The epistemic uncertainty of $\phi_{s s}$ was assumed to be normally distributed and was modeled using a three-point distribution that maintains the mean and standard deviation of the original distribution (e.g., a discrete distribution with values of mean-1.6 std, mean, and mean +1.6 std and weights of $0.2,0.6$, and 0.2 , respectively). Thus the high $\phi_{s s}$ was taken as the median $\phi_{s s}+1.6 \operatorname{std}\left(\phi_{s s}\right)$, and the low $\phi_{s s}$ was taken as the median $\phi_{s s}-1.6 \operatorname{std}\left(\phi_{s s}\right)$.

For $\tau$ there is a large spread in the published values in existing GMPEs, and there are no clear trends with the size of the database or with the degree of regionalization. For this reason, it was deemed appropriate to also consider epistemic uncertainty for $\tau$. The same degree of epistemic uncertainty was applied to $\tau$ as to $\phi_{s s}$ (e.g., the epistemic uncertainty on $\tau$ is modeled by a coefficient of variation of 0.1 and a threepoint distribution). The resulting high, median, and low models cover the range of $\tau$ values from published relationships.

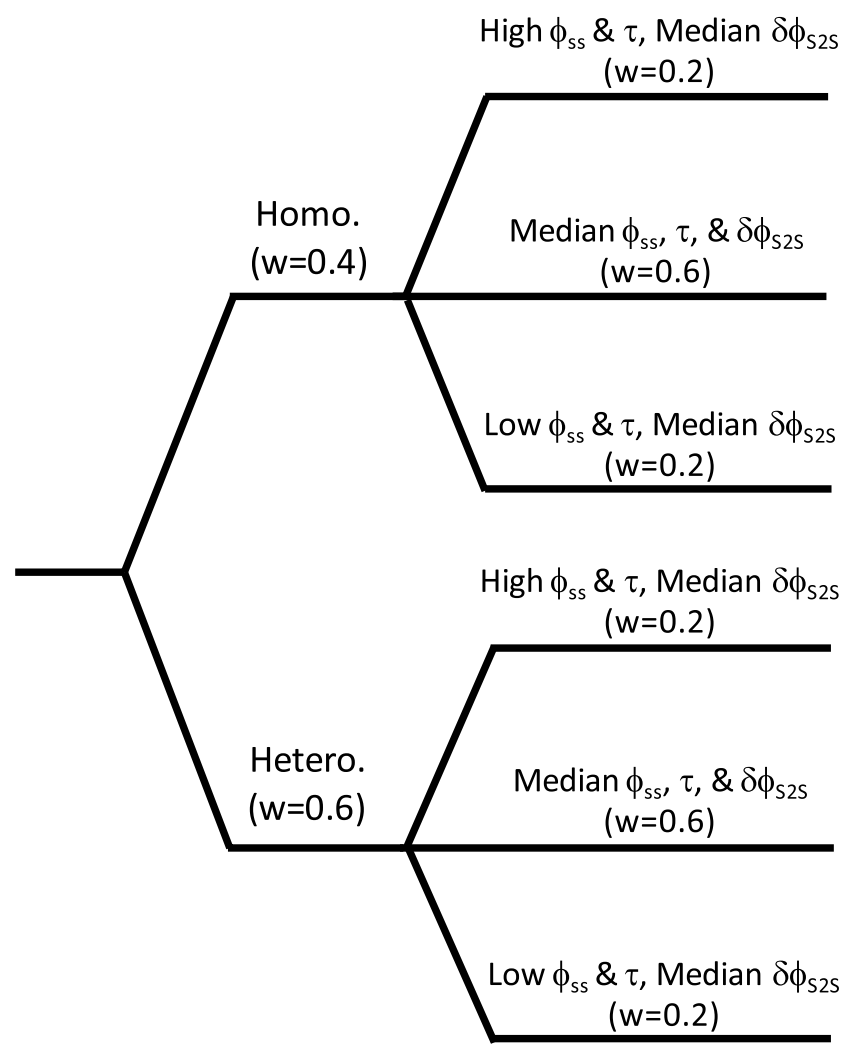

Figure 19. Schematic representation of the Thyspunt probabilistic seismic-hazard analysis sigma model.

It was also decided to couple the epistemic uncertainty on $\tau$ with the epistemic uncertainty on $\phi_{s s}$, such that the high $\phi_{s s}$ and high $\tau$ were used together, as were the low $\phi_{s s}$ and low $\tau$. The final sigma logic tree is shown in Figure 19.

\section{Discussion and Conclusions}

Among the most important developments in seismichazard assessments in the last two decades have been the great advances in understanding and accounting for uncertainties in the estimation of ground motions used as input to engineering design and assessment. A key step in this process was the clear distinction between aleatory variability and epistemic uncertainties, allowing each to be addressed in an appropriate fashion. Aleatory variability is directly incorporated into the integrations performed within PSHA, which is becoming the global standard despite some regulatory guidelines that sustain the parallel practice of deterministic hazard assessments (e.g., International Atomic Energy Agency [IAEA], 2010). Epistemic uncertainties are now routinely incorporated into PSHA studies through the use of logic trees (e.g., Bommer and Scherbaum, 2008), and there are guidelines on how to conduct multi-expert assessments to populate and assign weights to the branches of logic trees (USNRC, 2012).

Now that uncertainties are being more completely accounted for in seismic-hazard studies, attention has become 
more focused on ways to diminish the uncertainties. Theoretically, only epistemic uncertainty can be reduced through the collection of more data, because aleatory variability represents the inherent randomness in earthquake processes. However, there are elements of aleatory variability that are treated as being random (or which appear as random with respect to the models employed) but are in fact epistemic uncertainties. Transforming such elements from aleatory variability to epistemic uncertainty opens the possibility for their subsequent reduction through data collection. A very promising development in this regard has been the introduction of the concepts of single-station and single-path sigma in ground-motion prediction. The single-station sigma concept can be invoked if the epistemic uncertainty in the sitespecific component of the ground-motion predictions can be accounted for in the modeling of site effects, both for the near-surface materials and the deeper site profile.

This paper has described the incorporation of $V_{S}-$ kappa adjustments, site-response analyses, and single-station sigma in the ground-motion model developed for the PSHA carried out for a nuclear site in South Africa. The use of site-specific $V_{S}$-kappa adjustments and site-response analyses, as well as the inclusion of epistemic uncertainty in the $V_{S}$-kappa adjustments and the variability in the site AFs, allowed the project to adopt the partially nonergodic PSHA approach and hence use single-station sigma. The single-station sigma concept has been proposed only recently, and this project is one of the first to adopt it. The use of single-station sigma prevented the artificial inflation of uncertainty that can result from compounding the ground-motion and site-response components of uncertainty. The framework used in this project can serve as a model for the rigorous treatment of epistemic uncertainty for site-specific analysis in regions without a significant number of ground-motion recordings.

The collection of a significant amount of shear-wave velocity data contributed toward the development of the reference rock velocity horizon and provided the data to constrain the shear-wave velocity model for the site-response analyses. In particular, the shear-wave velocity profiles allowed for the accurate quantification of the variability in $V_{S}$ across the site and the development of site-specific models for layer thickness and interlayer correlation. These elements are necessary to accurately model the epistemic uncertainty in the site response.

Weak-motion recordings played an important role in developing the seismological parameters $\kappa_{0}$ and $Q$ used in the $V_{S}$-kappa adjustments for the GMPEs. However, the limited frequency band of the available recordings and the use of recordings from sites with velocity conditions different than the reference rock conditions at the nuclear site resulted in significant uncertainty in the appropriate $\kappa_{0}$ values to use for the $V_{S}$-kappa correction. To remedy this situation for future projects, it is recommended to install suitable instruments at the surface and at depth at the reference rock velocity horizon. By suitable instruments we mean those with a flat response function at high frequencies, combined with a high sampling rate, which is not necessarily the case with socalled broadband seismographs (contrary to what the name might suggest). The borehole recordings will allow for direct measurement of $\kappa_{0}$ for the reference rock condition, and the combination of borehole and surface recordings will provide direct calculation of site amplification. These measurements will reduce the uncertainty in $\kappa_{0}$ and better constrain the site AFs. The installation of such instrument configurations may be costly and, to be useful to a PSHA, must be done as early as possible to increase the chances of obtaining recordings. This will therefore require considerable foresight on the part of project sponsors, but it could also bring very significant benefits in terms of reduced uncertainty in the HF region of the resulting response spectra, which may have important implications for nuclear facilities.

\section{Data and Resources}

Weak-motion recordings used to estimate values of kappa were obtained from the South African National Seismological Network (SANSN; http://www.geoscience.org.za, last accessed 4 July 2013). Shear-wave velocity profiles used for site-response analyses were obtained as part of the Thyspunt Nuclear Siting Project and are proprietary; however, these will be made publicly available in 2014 (see Bommer et al., 2014).

\section{Acknowledgments}

The authors of this paper are the members of the ground-motion characterization (GMC) Technical Integration Team for the Thyspunt probabilistic seismic-hazard analysis (PSHA). However, many others contributed to the success of this project. Erna Hattingh of the Council for Geoscience (CGS) in South Africa served as Project Manager and, supported by many colleagues from CGS, was instrumental in coordinating all aspects of this project. The shear-wave velocity testing was made possible by a large number of people. Artur Cichowicz, Denver Birch, Vincent Jele, Robert Kometsi, and Leonard Tabane of the CGS performed the multichannel analysis of surface waves (MASW) field work. Choon Park of Park Seismic, Inc. performed the final processing of the MASW data. Johann Neveling of CGS and Bruce Engelsman of SRK Consulting (http://www.srk.com/en, last accessed May 2014) provided invaluable logistical assistance and managed the boring operations for the $P S$ logging. Graham Comber of Robertson Geologging performed the $P S$ logging measurements.

We are also grateful to Jonathan Stewart and an anonymous reviewer for very constructive and insightful feedback that helped us to considerably improve the paper.

\section{References}

Abrahamson, N. A., and W. J. Silva (2008). Summary of the Abrahamson and Silva NGA ground-motion relations, Earthq. Spectra 24, no. 1, 67-97.

Akkar, S., and Z. Çağnan (2010). A local ground-motion predictive model for Turkey, and its comparison with other regional and global groundmotion models, Bull. Seismol. Soc. Am. 100, 2978-2995.

Al Atik, L., N. A. Abrahamson, J. J. Bommer, F. Scherbaum, F. Cotton, and N. Kuehn (2010). The variability of ground-motion prediction models and its components, Seismol. Res. Lett. 81, 794-801.

Anderson, J. G., and J. N. Brune (1999). Probabilistic seismic hazard assessment without the ergodic assumption, Seismol. Res. Lett. 70, 19-28. 
Anderson, J. G., and S. E. Hough (1984). A model for the shape of the Fourier amplitude spectrum of acceleration at high frequencies, Bull. Seismol. Soc. Am. 74, 1969-1993.

Atkinson, G. M. (2006). Single-station sigma, Bull. Seismol. Soc. Am. 96, 446-455.

Atkinson, G. M. (2008). Ground-motion prediction equations for eastern North America from a referenced empirical approach: Implications for epistemic uncertainty, Bull. Seismol. Soc. Am. 98, 1304-1318.

Bazzurro, P., and C. A. Cornell (2004). Nonlinear soil-site effects in probabilistic seismic hazard analysis, Bull. Seismol. Soc. Am. 94, 2110-2123.

Bommer, J. J., and N. A. Abrahamson (2006). Why do modern probabilistic seismic hazard analyses lead to increased hazard estimates? Bull. Seismol. Soc. Am. 96, 1967-1977.

Bommer, J. J., and F. Scherbaum (2008). The use and misuse of logic-trees in PSHA, Earthq. Spectra 24, 997-1009.

Bommer, J. J., K. J. Coppersmith, R. T. Coppersmith, K. L. Hanson, A. Mangongolo, J. Neveling, E. M. Rathje, A. Rodriguez-Marek, F. Scherbaum, R. Shelembe, P. Stafford, and F. O. Strasser (2014). A SSHAC Level 3 probabilistic seismic hazard analysis for a newbuild nuclear site in South Africa, Earthq. Spectra, doi: 10.1193/ 060913EQS145M.

Bommer, J. J., K. J. Coppersmith, E. Hattingh, and A. P. Nel (2013). An application of the SSHAC Level 3 process to the probabilistic seismic hazard assessment for the Thyspunt nuclear site in South Africa, in Proc. 22nd International Conference on Structural Mechanics in Reactor Technology (SMiRT22), San Francisco, California, 18-23 August 2013.

Boore, D. M., and G. M. Atkinson (2008). Ground-motion prediction equations for the average horizontal component of PGA, PGV, and 5\%-damped PSA at spectral periods between $0.01 \mathrm{~s}$ and $10.0 \mathrm{~s}$, Earthq. Spectra 24, 99-138.

Boore, D. M., and W. B. Joyner (1997). Site amplifications for generic rock sites, Bull. Seismol. Soc. Am. 87, 327-341.

Budnitz, R. J., G. Apostolakis, D. M. Boore, L. S. Cluff, K. J. Coppersmith, C. A. Cornell, and P. A. Morris (1997). Recommendations for probabilistic seismic hazard analysis: Guidance on uncertainty and the use of experts, NUREG/CR-6372, two volumes, U.S. Nuclear Regulatory Commission, Washington D.C.

Campbell, K. W. (2003). Prediction of strong ground motion using the hybrid empirical method and its use in the development of groundmotion (attenuation) relations in eastern North America, Bull. Seismol. Soc. Am. 93, 1012-1033.

Campbell, K. W., and Y. Bozorgnia (2008). NGA ground motion model for the geometric mean horizontal component of PGA, PGV, PGD, and $5 \%$ damped linear elastic response spectra for periods ranging from 0.01 to $10 \mathrm{~s}$, Earthq. Spectra 24, 139-171.

Chiou, B. S.-J., and R. R. Youngs (2008). An NGA model for the average horizontal component of peak ground motion and response spectra, Earthq. Spectra 24, 173-215.

Choi, W. K. (2008). Dynamic properties of ash-flow tuffs, PhD. Dissertation, University of Texas at Austin, Texas, $335 \mathrm{pp}$.

Cotton, F., F. Scherbaum, J. J. Bommer, and H. Bungum (2006). Criteria for selecting and adjusting groundmotion models for specific target regions: Application to central Europe and rock sites, J. Seismol. 10, no. $2,137-156$.

Darendeli, M. B., and K. H. Stokoe II (2001). Development of a new family of normalized modulus reduction and material damping curves, Geotechnical Engineering Report GD01-1, University of Texas at Austin, Texas.

Electric Power Research Institute (EPRI) (2013). Seismic Evaluation Guidance: Screening, Prioritization and Implementation Details (SPID) for the Resolution of Fukushima Near-Term Task Force Recommendation 2.1: Seismic, Report No. 1025287; available at http://www.epri.com/abstracts/ Pages/ProductAbstract.aspx?ProductId=000000000001025287 (last accessed May 2014).

Gasparini, D. A., and E. H. Vanmarcke (1976). SIMQKE: Simulated Earthquake Motions Compatible with Prescribed Response Spectra, Massachusetts Institute of Technology, Cambridge, Massachusetts.
International Atomic Energy Agency (IAEA) (2010). Seismic hazards in site evaluations for nuclear installations, in Specific Safety Guide SSG-9, International Atomic Energy Agency, Vienna, Austria, 60 pp.

Joyner, W. B., R. E. Warrick, and T. E. Fumal (1981). The effect of Quaternary alluvium on strong ground motion in the Coyote Lake, California, earthquake of 1979, Bull. Seismol. Soc. Am. 71, 1333-1349.

Kgaswane, E. M., A. A. Nyblade, J. Julià, P. H. G. M. Dirks, R. J. Durrheim, and M. E. Pasyanos (2009). Shear wave velocity structure of the lower crust in southern Africa: Evidence for compositional heterogeneity within Archean and Proterozoic terrains, J. Geophys. Res. 114, no. B12304, doi: 10.1029/2008JB006217.

Kottke, A. R., and E. M. Rathje (2008). Technical Manual for Strata, PEER Report 2008/10, Pacific Earthquake Engineering Research Center, University of California at Berkeley, $84 \mathrm{pp}$.

Ktenidou, O.-J., F. Cotton, N. Abrahamson, and J. G. Anderson (2013). Taxonomy of $\kappa$ : A review of definitions and estimation approaches targeted to applications Seismol. Res. Lett. 85, 135-146, doi: 10.1785/0220130027.

Lin, P.-S., B. S.-J. Chiou, N. A. Abrahamson, M. Walling, C.-T. Lee, and C.-T. Cheng (2011). Repeatable source, site, and path effects on the standard deviation for empirical ground-motion prediction models, Bull. Seismol. Soc. Am. 101, 2281-2295.

McGuire, R. K., W. J. Silva, and C. J. Costantino (2001). Technical basis for revision of regulatory guidance on design ground motions: Hazardand risk-consistent ground motion spectra guidelines, in NUREG/ CR-6728, U.S. Nuclear Regulatory Commission, Washington D.C.

Rathje, E. M., and M. C. Ozbey (2006). Site specific validation of random vibration theory-based site response analysis, ASCE J. Geotechn. Geoenviron. Eng. 132, no. 7, 911-922.

Rathje, E. M., A. R. Kottke, and M. C. Ozbey (2005). Using inverse random vibration theory to develop input Fourier amplitude spectra for use in site response, Proc., 16th International Conference on Soil Mechanics and Geotechnical Engineering: TC4 Earthquake Geotechnical Engineering Satellite Conference, Osaka, Japan, 12-16 September 2005, 160-166.

Renault, P., S. Heuberger, and N. A. Abrahamson (2010). PEGASOS Refinement Project: An improved PSHA for Swiss nuclear power plants, Proc. 14th European Conference of Earthquake Engineering, Ohrid, Republic of Macedonia, 30 August-3 September 2010, Paper ID 991.

Rodriguez-Marek, A., F. Cotton, N. A. Abrahamson, S. Akkar, L. Al Atik, B. Edwards, G. A. Montalva, and H. Dawood (2013). A model for single-station standard deviation using data from various tectonic regions, Bull. Seismol. Soc. Am. 103, 3149-3163.

Rodriguez-Marek, A., G. A. Montalva, F. Cotton, and F. Bonilla (2011). Analysis of single-station standard deviation using the KiK-net data, Bull. Seismol. Soc. Am. 101, 1242-1258.

Sandıkkaya, M. A., M. T. Yılmaz, B. S. Bakır, and Ö. Yılmaz (2010). Site classification of Turkish national strong-motion stations, J. Seismol. 14, 543-563.

Scasserra, G., J. P. Stewart, P. Bazzurro, G. Lanzo, and F. Mollaioli (2009). A comparison of NGA ground-motion prediction equations to Italian data, Bull. Seismol. Soc. Am. 99, 2961-2978.

Scherbaum, F., F. Cotton, and H. Staedtke (2006). The estimation of minimum-misfit stochastic models from empirical ground-motion prediction equations, Bull. Seismol. Soc. Am. 96, 427-445.

Schnabel, P. B. (1973). Effect of local geology and distance from source on earthquake ground motions, Ph.D. Dissertation, University of California at Berkeley, California.

Silva, W. J., N. A. Abrahamson, G. R. Toro, and C. Costantino (1997). Description and validation of the stochastic ground motion model, Final report, Brookhaven National Laboratory, Contract Number 770573, Upton, New York.

Strasser, F. O., J. J. Bommer, and N. A. Abrahamson (2008). Truncation of the distribution of ground-motion residuals, J. Seismol. 12, no. 1, 79-105.

Tezel, T., T. Shibutani, and B. Kaypak (2010). Crustal structure variation in western Turkey from receiver function analyses, Tectonophysics 492, $240-252$. 
Toro, G. R. (1995). Probabilistic models of site velocity profiles for generic and site-specific ground-motion amplification studies, Technical Report 779574, Brookhaven National Laboratory, Upton, New York.

Toro, G. R., N. A. Abrahamson, and J. F. Schneider (1997). Model of strong ground motions from earthquakes in central and eastern North America: Best estimates and uncertainties, Seismol. Res. Lett. 68, 41-57.

U.S. Nuclear Regulatory Commission (USNRC) (2007). A performancebased approach to define the site-specific earthquake ground motion, in Regulatory Guide 1.208, U.S. Nuclear Regulatory Commission, Washington, D.C.

U.S. Nuclear Regulatory Commission (USNRC) (2012). Practical implementation guidelines for SSHAC Level 3 and 4 hazard studies. NUREG 2117, U.S. Nuclear Regulatory Commission, Washington, D.C.

Van Houtte, C., S. Drouet, and F. Cotton (2011). Analysis of the origins of $\kappa$ (kappa) to compute hard rock to rock adjustment factors for GMPEs, Bull. Seismol. Soc. Am. 101, 2926-2941.

Virginia Tech

Charles E. Via, Jr.

Department of Civil and Environmental Engineering

Patton Hall, Rm. 214

750 Drillfield Drive

Blacksburg, Virginia 24061

adrianrm@vt.edu

(A.R.-M.)
University of Texas at Austin

Department of Civil, Architectural, and Environmental Engineering

301 E. Dean Keeton St, Stop C1700

Austin, Texas 78712

e.rathje@mail.utexas.edu

(E.M.R.)

Imperial College London

Department of Civil and Environmental Engineering

South Kensington Campus

London SW7 2AZ, United Kingdom

j.bommer@imperial.ac.uk

p.stafford@imperial.ac.uk

(J.J.B., P.J.S.)

Institut für Erd-und Umweltwissenschaften

Universität Potsdam

Karl-Liebknecht-Str. 24-25

14476 Potsdam-Golm, Germany

Frank.Scherbaum@geo.uni-potsdam.de

(F.S.)

Manuscript received 25 July 2013; Published Online 3 June 2014 